
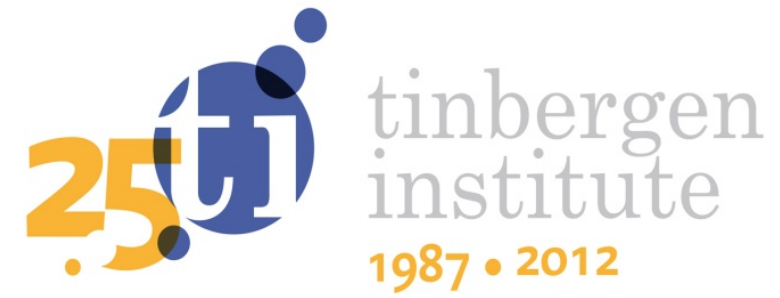

\title{
Composite Valuation of Immaterial Damage in Flooding: \\ Value of Statistical Life, Value of Statistical Evacuation and Value of Statistical Injury
}

Marija Bockarjoval

Piet Rietveld 1,2

Erik Verhoefl,2

' Faculty of Economics and Business Administration, VU University Amsterdam,

2 Tinbergen Institute. 
Tinbergen Institute is the graduate school and research institute in economics of Erasmus University Rotterdam, the University of Amsterdam and VU University Amsterdam.

More TI discussion papers can be downloaded at http://www.tinbergen.nl

Tinbergen Institute has two locations:

Tinbergen Institute Amsterdam

Gustav Mahlerplein 117

1082 MS Amsterdam

The Netherlands

Tel.: +31(0)205251600

Tinbergen Institute Rotterdam

Burg. Oudlaan 50

3062 PA Rotterdam

The Netherlands

Tel.: +31(0)10 4088900

Fax: $+31(0) 104089031$

Duisenberg school of finance is a collaboration of the Dutch financial sector and universities, with the ambition to support innovative research and offer top quality academic education in core areas of finance.

DSF research papers can be downloaded at: http://www.dsf.nl/

Duisenberg school of finance

Gustav Mahlerplein 117

1082 MS Amsterdam

The Netherlands

Tel.: +31(0)20 5258579 


\section{Composite valuation of immaterial damage in flooding: value of statistical life, value of statistical evacuation and value of statistical injury}

\section{Bočkarjova}

VU Amsterdam, Faculty of Economics and Business Administration, Department of Spatial Economics, de Boelelaan 1105, 1081 HV Amsterdam, The Netherlands. Email: m.bockarjova@,vu.nl tel. +31 205986142 , fax +31205986004 (corresponding author)

\section{P.Rietveld*}

VU Amsterdam, Faculty of Economics and Business Administration, Department of Spatial Economics, de Boelelaan 1105, 1081 HV Amsterdam, The Netherlands. Email: p.rietveld@,vu.nl

\section{E.Verhoef*}

VU Amsterdam, Faculty of Economics and Business Administration, Department of Spatial Economics, de Boelelaan 1105, 1081 HV Amsterdam, The Netherlands. Email: e.t.verhoef@,vu.nl

* Tinbergen Institute.

\section{Abstract}

This paper enriches existing valuation literature in a number of ways by presenting context-specific estimates of immaterial damage. First, it offers an estimation of value of statistical life (VOSL) in the context of a natural hazard (flooding). Next, as one of the contributions, alongside with less biased estimate of VOSL (€6.8 mln) it also provides estimates of the value of statistical injury (VOSI, €92,000), and of the value of statistical evacuation (VOSE, $€ 2,400$ ).

Our estimated indicators are plausible and stay robust throughout various estimations. For flood protection policy in the Netherlands, a higher value of VOSL forthcoming from this research would imply 'underprotection' under current conditions. Another important finding concerns the composition of the total value of immaterial damages, where value of fatalities or value of evacuation may dominate depending on the prevailing floor risk circumstances. This implies that, first, VOSL is not an adequate proxy for immaterial damages since it understates prospective benefits of designated protective measures. Second, spatially differentiated composition of immaterial damages should be explicitly considered to guide policy decisions.

Key words: cost-benefit analysis, natural hazard, flood risk, stated preferences, choice experiment. 


\section{Introduction}

Flood disasters pose the biggest threat to the Netherlands among all natural hazards. And while the Dutch boast a long history of advanced flood protection, it continuously remains a matter of choices whether or not to make improvements to the current system. Thus, decisions should regularly be made with regard to which new protection elements to install, which to enforce, where and when. In the context of climate change and uncertainties related to the sea level rise, the ultimate art is to find some optimal level of protection also meeting future climate challenges (Costanza and Farley, 2007). This means that decision-making tools need to become ever more accurate so that adequate and financially sound decisions are made. Often, cost-benefit analyses (CBA) are used for these purposes (van Dantzig, 1956; Wijnen et al., 2009).

One of the elements in cost-benefit analyses that as yet remains a subject of debate is the benefit of avoided immaterial damages, such as human losses (that is often monetized as the value of statistical life, VOSL or VSL, see definition in Section 4). Because an estimation of the VOSL is not always available in the context of a particular risk, it may be adopted from another context. So, in the Netherlands VOSL from transport safety is used in CBA of flood protection measures (Wijnen et al., 2009). This benefit transfer from one context to another offers but an approximation of VOSL. Also contemporary literature presents conflicting evidence on potential usefulness of benefit transfer to policymakers (Richardson and Loomis, 2009, Baskaran et al., 2010, Alberini and Šcasný, 2011, Dekker et al., 2011). While valuation of VOSL might in theory be expected to stay stable independently of risk context, space or time, empirical studies witness differences in such valuations throughout risk contexts, countries and various moments in time. This means that no universal VOSL value exists; rather an adequate value of benefit of one expectedly avoided fatality should at best be measured in the particular context if major policy decision is to be made (Baskaran et al., 2010). For this matter, estimations of immaterial damage in flood risk context are scarce also internationally, and to the knowledge of the authors, are not directly comparable with the situation in the Netherlands (for example, Zhai $2006^{1}$ ). Provided the need for immaterial damage indicators for flood safety

\footnotetext{
${ }^{1}$ Floods in Japan, studied by Zhai (2006) are more frequent and thus more common events than floods in the Netherlands where flood probabilities are extremely low. This poses an additional degree of complexity on risk
} 
context, we have undertaken a research in this area. One of the issues that characterizes this risk context is the presence of correlated risks. The problem in the elicitation of such risks is that risk valuation may be confounded if only fatality risk is valued. ${ }^{2}$

The objective of this paper is to estimate three immaterial damage indicators in the context of flood risk in the Netherlands and to provide composite valuation of immaterial damages. ${ }^{3}$ We consider value of statistical life (VOSL), value of statistical evacuation (VOSE) and value of statistical injury (VOSI). This research is novel in a number of aspects. First, we provide an estimation of VOSL in flooding. VOSL is one of the essential components entering cost-benefit analyses as a (best available) approximation of value of benefit of an avoided (or, rather, delayed) fatality in a particular risk context. This is one of the first efforts to elicit VOSL in the estimation context of natural hazards. Although we did not explicitly frame the valuation questions in terms of climate change, increasing flood risk in the Netherlands is a number one consequence of the climate change and thus this research can be positioned in the row of literature addressing monetary valuation of immaterial damages due to global warming (see for example Frankhauser and Tol, 1996; Frankhauser, Tol and Pearce, 1998).

Another important contribution of this paper is a separate valuation of a fatality risk and a risk of getting an injury on the one hand, and valuation of a risk of getting evacuated on the other hand. For example, risk of evacuation, risk of getting an injury and, on individual level, risk of fatality are related and cannot be realized all at once; so if someone is evacuated from a flood-prone area, she cannot get an injury or die as a result of a flood; also, if someone could not get evacuated, then she runs a risk of getting an injury and a risk of becoming a fatal victim, as yet only one of the two can get realized. ${ }^{4}$ It is sometimes being suggested that VOSL estimates might be biased, or confounded, due to sensitivity of willingness to pay (WTP) to the scope of goods valued (see for example Svensson, 2009) as respondents implicitly include the

valuation performed with the help of stated preference methods (as pointed out inter alia by Hammit, 1999). This requires more cognitive effort on behalf of respondents and may have a significant impact on risk valuation. This issue is addressed in more detail in Bočkarjova et al. 2010).

${ }^{2}$ We address the issue of confounded risk valuation in Bočkarjova et al. (2010) where we confirm VOSL sensititvity to the presence of correlated risks for some sub-groups of respondents.

${ }^{3}$ Also studies on valuation of material damages connected to flood hazard in the Netherlands have become available recently (Botzen et al., 2009 and Daniel et al., 2009).

${ }^{4}$ Essentially, injuries are also possible during evacuations as well. This is however a topic that is not broadly studied; an estimate of injured persons per evacuation is at best approximated by a number of traffic victims, see for example Kolen et al. (2010). In our case, to reduce the complexity of the choice experiment, we have decided to omit this detail and deal only with cases of evacuation, injury and fatality that are exclusive at the individual level. 
valuation of a other risks related to a calamity when only VOSL is being measured. Explicit valuation of injury (VOSI) and evacuation (VOSE) alongside with VOSL helps addressing this issue. This means that we are able to arrive at indicators that are closer to the 'true' values of VOSE, VOSI and VOSL, which in turn will facilitate taking better public decisions concerning risk reduction measures and therefore should result in increased collective welfare.

This paper is organized as follows. We shall first provide a description of the choice experiment conducted in the Netherlands. Then, we shall describe the model and provide a short summary of multinomial logit estimations, followed by a discussion of results obtained from advanced mixed logit estimations of VOSL, VOSI and VOSE, and concentrate in particular on the VOSL values. Next, we shall provide calculations for composite valuation of immaterial damage for two representative areas. The paper will be finalized with conclusions and policy implications.

\section{The methodology}

Stated preference modeling (SP), and in particular choice experiments, is one of the state-of-the-art techniques that is currently widely used in valuation of intangible goods for which (directly or indirectly) no markets exist. Because of non-existent markets, realized choices of consumers cannot be observed, and therefore their 'revealed preferences' cannot be measured, at least not directly. Using SP methodology, the researcher creates a setting where, depending on the context, (artificial) goods are traded in artificial markets. By asking respondents to make choices in such situations, their intended behaviour is obtained, from which 'stated preferences' can be derived. The areas where SP is widely used include environmental studies, health care, transport and labour economics (see for example de Blaeij et al., 2003; Dekker et al., 2011; Kluve and Schaffner, 2008; Bellavance et al., 2009). The VOSL that is derived by means of these techniques is often used in cost-benefit analyses as a (best available) approximation of value of an avoided fatality in a particular risk context (see Viscusi and Aldy, 2003).

When a choice experimental setting is applied, respondents usually receive some general information about the nature of risk, as well as some explanation of the present average risk level. This is done in an effort to obtain well-informed choices in a clearly defined situation. Choice cards usually present a number of alternatives defined by the researcher. The choice cards are constructed in such a way that there is enough 
variation in attribute levels (such as risk and monetary payment) to be able to value individual choice parameters.

\subsection{The choice experiment}

Our study was carried out using an internet questionnaire conducted in October-November 2008 among about 530 respondents located in four regions of the country (see Figure 1): coastal areas of Central Holland and Zeeland; and riverside areas of island of Dordrecht and the Betuwe (Land van Heusden / de Maaskant). The overall sample as well as regional sub-samples are representative and were drawn from a commercial respondent panel (TNS-NIPO, see Table 1).

Table 1. Overview of demographic characteristics of respondents in the sample.

\begin{tabular}{|l|r|}
\hline \multicolumn{1}{|c|}{ Demographic variable } & Sample average \\
\hline Males & $38.55 \%$ \\
\hline Rural inhabitants & $10.06 \%$ \\
\hline Higher education & $29.05 \%$ \\
\hline High income $^{\mathrm{a}}$ & $16.76 \%$ \\
\hline Income not stated $^{\prime}$ & $30.73 \%$ \\
\hline Age $18-34$ & $13.78 \%$ \\
\hline Age $35-64$ & $32.03 \%$ \\
\hline Age 65 and older & $54.19 \%$ \\
\hline Excellent health condition ${ }^{\mathrm{b}}$ & $58.85 \%$ \\
\hline N respondents & 537 \\
\hline
\end{tabular}

a High income measured as respondents with income in 8th-10th deciles of national income distribution. ${ }^{\mathrm{b}}$ Self-estimated health condition, measured at 8 to 10 on a scale from 0 to 10 . 


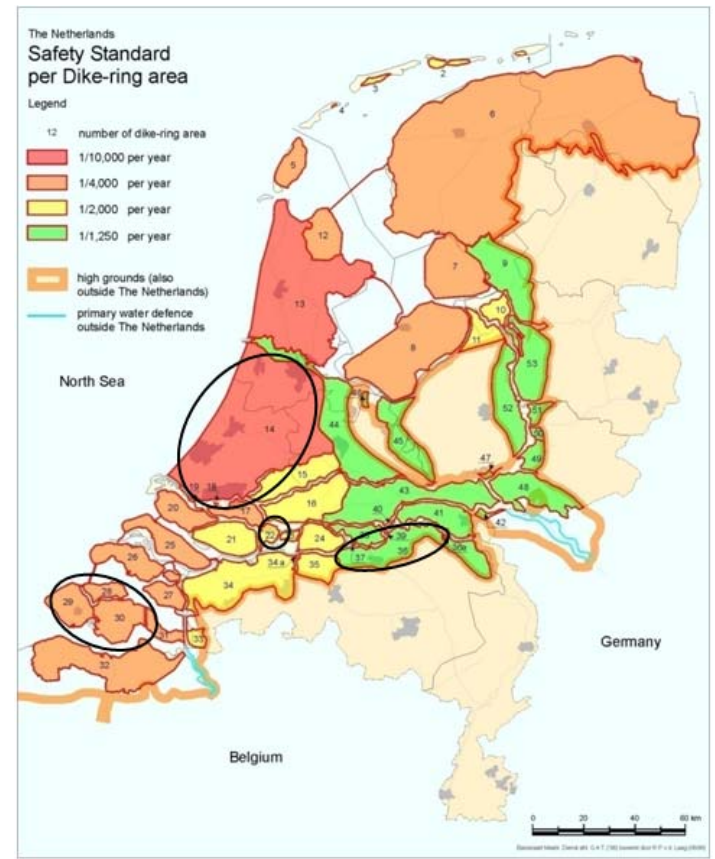

Figure 1. Map of the Netherlands with safety standards for the dike-rings. Surveyed areas circled.

Before presenting respondents with hypothetical choices on their flood safety, we first provided them with extended textual and visualized information about the actual average yearly probability of flooding, the probability of dying in an event of flood, and the yearly probability of fatality due to flooding in their place of residence. The probabilities varied depending on the specific dike-ring (see Table 2).

Table 2. Average assumed probabilities per dike-ring area

\begin{tabular}{|c|c|c|c|}
\hline & $\begin{array}{c}\text { Overtopping } \\
\text { probability (yearly) }\end{array}$ & $\begin{array}{c}\text { Probability of dying } \\
\text { in an event of } \\
\text { flood }^{\mathrm{a}, \mathrm{b}}\end{array}$ & $\begin{array}{c}\text { Probability of } \\
\text { fatality due to } \\
\text { flooding (yearly) }\end{array}$ \\
\hline $\begin{array}{c}\text { dike-ring 14 } \\
\text { (Zuid Holland) }\end{array}$ & $1: 10,000$ & $1 \%$ & $1: 1,000,000$ \\
\hline $\begin{array}{c}\text { dike-rings 28, 29, 30 } \\
\text { (Zeeland) }\end{array}$ & $1: 4,000$ & $1 \%$ & $1: 400,000$ \\
\hline $\begin{array}{c}\text { dike-ring 22 } \\
\text { (Dordrecht) }\end{array}$ & $1: 2,000$ & $0.1 \%$ & $1: 2,000,000$ \\
\hline $\begin{array}{c}\text { dike-ring 36 } \\
\text { (Land van Heusden / } \\
\text { de Maaskant) }\end{array}$ & $1: 1,250$ & $0.1 \%$ & $1: 1,250,000$ \\
\hline
\end{tabular}

${ }^{a}$ Mortality rates per dike-ring in the Netherlands were defined based on Klijn et al. (2004), WL|Delft Hydraulics (2007) and Jonkman et al. (2009).

${ }^{\mathrm{b}}$ While explained probabilities of dying given an event of flooding do vary by dike-ring ( $1 \%$ for the coastal areas and $0.1 \%$ for the riverside areas), shown yearly probabilities of dying due to flood in the choice cards are the same for all respondents, and are fixed in this choice experiment to $1 \%$ of the yearly probability of flooding.

In addition to explaining actual probabilities also visual aids such as probability grids and a risk ladder were provided. In a so-called risk ladder the probability of fatality due to flooding was brought in 
perspective with other average yearly risks of dying in the Netherlands. ${ }^{5}$ After that, the choice situation was explained and respondents were offered the choice cards. The design was generated in Sawtooth software (complete enumeration method), and its levels are balanced. It is an orthogonal design, that produces unbiased estimates for simulated responses. The design consists of 15 blocks, so that each respondent was presented with 5 cards containing two (labeled) alternatives.

This choice experiment included 2 alternatives; 'status quo' or an 'opt-out' alternatives were not necessary in our case as we were aiming at valuing particular attributes of the choices (like risk of fatality, risk of injury or evacuation) to obtain valuation of changes in risk around the current risk level, and not the value of the entire alternative. Also, the valuation we were performing did not have to do with the provision of a new good (which may or may not be acquired), but rather incremental changes in the existing good (flood protection), which is in fact a public good supplied to all residents of the flood-prone areas. Thus, we were able to avoid the reference point bias connected to the presence of a 'status quo' alternative (Chernev, 2004), and the non-response bias connected to the presence of an 'opt-out' alternative (Kontoleon and Yabe, 2003, Bonnichsen and Ladenburg, 2010).

Our respondents were asked to make a choice - a 'purchase decision' - between two hypothetical houses that were suggested to be similar in any other respect, yet different in terms of flood safety characteristics (see the precise wording of the choice situation in Appendix A). These characteristics, or choice attributes, describing the place of residence depended on the type of alternative. In one of the locations (alternative A) there was a possibility for a timely evacuation from the area before a flood, and thus this alternative was described by a flood risk (in the coming 50 years), evacuation risk described by a probability of preventive evacuation (in the coming 50 years) and the level of water board tax, or yearly payment. The other alternative did not presuppose evacuation (area $\mathrm{B})^{6}$ and therefore it was described by a flood risk (in the coming 50 years), fatality risk described by a probability of dying due to flooding (expressed in terms of average number of fatalities per 400.000 inhabitants in the coming 50 years), risk of injury (expressed in terms of average number of injured persons per 400.000 inhabitants in the coming 50

\footnotetext{
${ }^{5}$ Before the final version of the questionnaire was administered, it went through a pilot testing in a focus group. Report on the pilot survey is found in Bočkarjova et al. (2008a).

${ }^{6}$ Studies on evacuation in the Netherlands support an argument for impossibility of evacuation in coastal areas, see Jonkman (2007); Kolen and Helsoot (2011).
} 
years) and payment described as the respective level of water board tax per year in euros. The following numbers of attribute levels were considered in this choice experiment: $\mathrm{P}($ evacuation): 5 levels; $\mathrm{P}$ (fatality) attribute: 5 levels; P(injury): 5 levels; Tax attribute: 3 levels (see Appendix B for the levels). This was a second experiment in a row for these respondents (see Bočkarjova et al., 2010 for an analysis of the other experiment).

\section{The model}

In discrete choice modeling it is assumed that respondents attach some particular level of utility to each presented alternative, and that the choice is made in favour of an alternative with higher utility. Usually (Henscher et al., 2008), a respondent's $m$ utility of alternative $i$ is defined as $U_{i m}=V_{i m}+\varepsilon_{i m}$, where $V_{i m}$ part is observed (and thus can be measured) by the researcher via the predefined attributes of the alternative, and $\varepsilon_{i m}$ is the unobserved part of respondent's utility of alternative $i$, which accounts for all other properties of the alternative not included by the researcher.

In this choice experiment we offered respondents a choice between two houses, similar otherwise, but different in terms of flood safety: one is located in an area where preventive evacuation is possible, and another area where no evacuation is possible, and therefore all inhabitants run some risk of being injured during a flood or of dying in a flood. Thus, we have two labeled alternatives, different in 4 attributes: the first alternative includes the probability of evacuation in a polder $-x_{P e v}$ and the municipal tax level, $x_{T}$. The second one with the probability of injury $-x_{P i n j}$; the probability of fatality due to flooding $-x_{P f}$; and the respective level of local tax per year in euros $-x_{T}{ }^{7}$ The second alternative includes the $A S C$, the alternative specific constant. Therefore, respondent's $m$ utility function can be written for each alternative as:

$$
\begin{aligned}
& V_{m}(\text { evacuation })=A S C+\beta_{P e v} \cdot x_{P e v}+\beta_{T} \cdot x_{T} \\
& V_{m}(\text { no evacuation })=\beta_{P f} \cdot x_{P f}+\beta_{P i n j} \cdot x_{P i n j}+\beta_{T} \cdot x_{T}
\end{aligned}
$$

Note that $A S C$ in [1a] captures the difference in individual utility between the two labeled alternatives (in our case, the alternative that provides a possibility for evacuation compared to the one that does not). Inclusion of $A S C$ (evacuation) also means that respective coefficients of choice attributes will capture the

\footnotetext{
${ }^{7}$ For reasons of ease of explicability, also $\mathrm{P}($ flood) was shown on the card for each alternative, which was 100 times greater than $\mathrm{P}$ (fatality), corresponding to $1 \%$ fatality rate at the event of a flood.
} 
marginal valuation of the particular attribute. Also note that the monetary attribute in the two utility equations has the same coefficient, $\beta_{T}$, which presumes the same marginal utility of money for all respondents across both alternatives.

When beta coefficients in the utility functions are estimated, our indicators of interest can be obtained. In a basic model as defined by [1a,b], the VOSL, which is a trade-off between money and a decrease in risk level at the margin. Essentially, VOSL is a marginal rate of substitution between risk and welfare, and is thus determined as the marginal utility of fatality risk divided by the marginal utility of money to the respondents, so that:

$$
V O S L=\frac{\partial U / \partial x_{P f}}{\partial U / \partial x_{T}}=\frac{\beta_{P f}}{\beta_{T}}
$$

We emphasise that, as [2] makes clear, the VOSL is not a monetary value of a human live; it rather represents an average willingness to pay of a group of people for a marginal reduction in their average mortality risk. Because we are talking in statistical terms about a reduction of yearly expected number of fatalities, aggregate willingness to pay can be expressed as an amount of money per single avoided premature 'statistical' death, which is in fact VOSL.

Similar to the VOSL, the value of a statistical evacuation, VOSE, is the monetized benefit of an avoided inconvenience associated with a preventive evacuation when flood is expected. It is determined as the marginal utility of evacuation inconvenience divided by the marginal utility of money to respondents, so that $\operatorname{VOSE}=\beta_{P e v} / \beta_{T}$. Furthermore, this experiment allows computing the value of a statistical injury, VOSI, which is a trade-off between money and a decrease in the probability of an injury risk at the margin, is therefore determined as the marginal utility of inconvenience due to injury divided by the marginal utility of money to respondents: $V O S I=\beta_{\text {Pinj }} / \beta_{T}$. This means, that the goal of running model $[1 \mathrm{a}, \mathrm{b}]$ is the estimation of respective attribute beta's, where the ratios $\left(\beta_{P f} / \beta_{T}, \beta_{P e v} / \beta_{T}\right.$ and $\left.\beta_{P i n j} / \beta_{T}\right)$ provide an estimate of the indicators in question, VOSL, VOSE and VOSI, respectively.

\section{Results}

\subsection{Valuing flood risk: MNL estimations}


To elicit individual preferences with regard to flood risk in the Netherlands, we have a choice experiment with two labeled alternatives: one with the possibility for precautionary evacuation, and another without such a possibility. A basic multinomial logit (MNL) model run for this experiment showed that respondents' choices between the suggested alternatives were governed by the changes in the risk of evacuation, the risk of flooding and the tax; the risk of injury remained statistically insignificant in all basic estimations. Moreover, the statistically significant alternative-specific constant testifies of systematic preferences of respondents towards the alternative with an evacuation possibility provided the assumption on linear coefficients. Alternatively, ASC may be reflecting the non-linearity of the marginal utilities of risks. ${ }^{8}$

Table 3. Overview of main MNL estimates $\left(\mathrm{CI}_{95 \%}\right.$ in parenthesis $\left.{ }^{\mathrm{a}}\right)$.

\begin{tabular}{|c|c|c|}
\hline & $\begin{array}{c}\text { Basic } \\
\text { MNL model }\end{array}$ & $\begin{array}{c}\text { Extended } \\
\text { MNL model }^{\text {b }}\end{array}$ \\
\hline VOSL (value of statistical life) & $\begin{array}{r}€ 6.84 \mathrm{mln} \\
(4.126-9.543)\end{array}$ & $\begin{array}{r}€ 7.04 \mathrm{mln} \\
(3.114-10.966)\end{array}$ \\
\hline VOSI (value of stat. injury) & $\begin{array}{r}€ 92,183 \\
(-30,092-214,458)\end{array}$ & $\begin{array}{r}€ 95,689 \\
(-25,881-217,258)\end{array}$ \\
\hline VOSE (value of stat. evacuation) & $\begin{array}{r}€ 2,517 \\
(1,116-3,919)\end{array}$ & $\begin{array}{r}€ 2,554 \\
(1,345-3,762)\end{array}$ \\
\hline
\end{tabular}

a calculated using the delta method.

$\mathbf{b}$ indicators are weighted at covariate sample means

The average value of statistical life, VOSL, in our basic MNL logit estimations is about $€ 6.8 \mathrm{mln}$ - see Table 3 (which is within an expected range of $€ 2$ to $€ 14 \mathrm{mln}$ for European studies, see Kluve and Schaffner, $\left.2008^{9}\right)$; the average value of evacuation inconvenience, VOSE, is $€ 2,500$; the average value of injury, VOSI, is $€ 92,200$ (which might be seen as slightly high for a middle-range injury, but yet in the range of values

\footnotetext{
${ }^{8}$ We tested for and found evidence in favor of non-linearity in marginal utilities of risks depending on the risk level using dummy variables (results not reported in this paper but are available from the authors on request).

${ }^{9}$ In the view that our estimated VOSL excludes a part of immaterial damages that might otherwise be implicitly included in the valuation, such as the value of evacuation or value of injury due to flooding, it might be considered slightly high. This may be caused by money-risk trade-offs that involve unusually small changes in probability used in our experiment (in the order of $1,5^{*} 10^{-6}$ to $9^{*} 10^{-6}$ ) - as found by de Blaeij et al. (2003), VOSL decreases underproportionally as the valuated change in risk decreases. Another cause may be perhaps the willingness to avoid flood catastrophe as a no-'rival rationality' condition for valuation (following Sustein (2000, pp.30-31), other no-'rival rationality' conditions for people to be willing to pay a higher premium are: i) to avoid deaths that involve a high degree of pain and suffering; ii) to protect children; iii) to devote more resources to protect against dangers when the costs of risk avoidance are high; iv) to protect vulnerable or traditionally disadvantaged groups against certain risks ).
} 
found elsewhere in the literature, like Viscusi and Zeckhauser $1994^{10}$ and Shanmugam 2000, as well as de Brabander 2007). Statistical insignificance of risk of injury parameter (see Table C1) might be due to variations in individual interpretations of the term 'injury', which due to the character of possible injuries received in flooding was not described explicitly as a light or a heavy injury, but rather as a middle-range injury (see Ahern et al. 2005). Another possibility is correlations in valuation with other experiment attributes. This will be captured by estimating mixed logit models discussed in the following sections. Splitsample analysis (basic model) revealed significant differences in valuation of flood risk among respondents with various education levels, age and health condition.

An extended model was run to test the main effects of the independent covariates of our interest, such as income, age, education, gender, health condition, prior water-calamity experience and place of residence. The utility functions in the model then take the form:

$$
\begin{gathered}
V_{m}(\text { evacuation })=A S C+\beta_{P e v} \cdot x_{P e v}+\beta_{T} \cdot x_{T}+\sum \beta_{Y i} \cdot\left(x_{Y i} \cdot x_{T}\right) \\
\begin{array}{c}
V_{m}(\text { no evacuation })=\beta_{P f} \cdot x_{P f}+\beta_{P i n j} \cdot x_{P i n j}+\beta_{T} \cdot x_{T}+ \\
\sum \beta_{Y i} \cdot\left(x_{Y i} \cdot x_{T}\right)+\sum \beta_{Z i} \cdot\left(x_{Z i} \cdot x_{P f}\right)
\end{array}
\end{gathered}
$$

Where the three summation terms represent independent variable interactions with one of the experiment attributes: $\sum \beta_{Z i} \cdot\left(x_{Z i} \cdot x_{P f}\right)$ stands for interaction terms of covariates $x_{Z i}$ with risk attributes $\mathrm{P}($ fatality $) .{ }^{11}$ The other term, $\sum \beta_{Y i} \cdot\left(x_{Y i} \cdot x_{T}\right)$, stands for interaction terms of covariates $x_{Y i}$ with the monetary attribute Tax.

Table C2 in the Appendix shows the results of this extended MNL model. In the extended model where multiple covariates were included simultaneously, only effects of age and health condition prevailed (with education effect faded away), and the effect of own prior experience with flood or evacuation gained prominence. While the age and health condition relations with willingness to pay for decreases in risk were not unexpected (WTP increases with age, and decreases as the individual's estimation of the own health

\footnotetext{
${ }^{10}$ Viscusi and Zeckhauser (1994, p.35) in their revealed preference study of injury valuations use a similar definition of injury, and also find similar monetary valuations of injury: "In the case of injury valuations, the midpoint estimate for an injury severe enough to lead to a lost workday (which of course includes much more severe injuries as well) is 50,000 USD. ... Empirical estimates suggest that the social value of injuries may be $50 \%$ larger than this amount."

${ }^{11}$ In the process of selection of the preferred model, we have also tested MNL models where covariate interactions were included with the other two risk attributes, $\mathrm{P}$ (injury) and $\mathrm{P}$ (evacuation). These interaction, however, remained insignificant and are therefore not considered in the preferred model [3a,b].
} 
condition improves) ${ }^{12}$ the association between prior experience with floods and WTP turned out to be somewhat surprising. The negative sign of this coefficient may be due to either 'adverse availability heuristic' (underestimation of individual future probability of getting repeatedly involved in similar events), or 'calamity impact discounting' (underestimation of future calamity impact due to minor damages incurred in a similar event in the past), see Bočkarjova et al. (2009).

In the next sections we shall report on our main findings based on the mixed logit estimations.

\footnotetext{
${ }^{12}$ In the test phase, age, health and gender dummies were also interacted with the risk attributes, but this did not yield statistically significant results. So, in the preferred extended MNL model, as shown in Table C2, the covariates that are interacted with the tax attribute are: high income, no income stated, age, health condition, gender and own property; the covariates that are interacted with the $\mathrm{P}($ fatal $)$ attribute are: rural, coastal area and prior experience.
} 


\subsection{Valuing flood risk: mixed logit estimations}

We use the mixed logit model to estimate the models of the type [1a,b] and [3a,b] (basic and extended versions, respectively). This means that one or more of the choice attributes will be assumed to vary randomly following a specified distribution, in order to capture individual heterogeneity in risk valuation, such that $\beta \sim f(\beta \mid \theta)$, where $\theta$ stands for characteristic parameters (such as mean and variance) of the respective distributions of the choice coefficient $\beta$ over the population. The assumed mixing distributions are often normal, uniform, triangular or lognormal. For all models we have included a panel structure, and the models were estimated using the Limdep 4.0 software.

We have estimated a number of models before choosing the preferred model formulation (which will be discussed in the next section).

We have assumed first that individuals might differ in their valuation of the two alternatives in our labeled experiment. Thus, the alternative specific constant for the alternative with possibility of evacuation (ASC(evacuation)) was set random, following normal, triangular and uniform distributions (all with 1,000 Halton draws). All of these models were similar in terms of resulting in a substantial improvement in loglikelihood, and showing statistically significant coefficients for the constant term as well as for its standard deviation. Both results point at the presence of heterogeneity in tastes among the respondents regarding the valuation of the two alternatives. Also we could observe both positive and negative valuations of the constant term, which means that there are respondents who ex ante would prefer an alternative with a possibility for evacuation with a preference for zero probability of premature death (which provides a safety feeling), while other respondents are rather inclined to choose an alternative without such a possibility to avoid any evacuation inconvenience, in exchange accepting some small positive probability of a fatal outcome. However, the majority of respondents ( $60 \%$ to $80 \%$, depending on the underlying distribution) had a positive valuation of the constant term.

As a next step, in addition to the random $A S C$ parameter, we have let three risk attribute coefficients be random for the risk of fatality $\left(\beta_{P f}\right)$, risk of injury $\left(\beta_{P i n j}\right)$ and risk of evacuation $\left(\beta_{P e v}\right)$, and we again checked for various mixing distributions for the risk parameters assuming normal, triangular, uniform and lognormal distributions (all with 1.000 Halton draws). To limit the number of model variants, alternative specific constant in the utility function of the alternative with the possibility of preventive evacuation was set random 
with normal mixing distribution. In all these models, alongside with the assumed panel structure of the data, we have also looked at possible correlations between the four random choice attributes. For all models we could again see a substantial improvement in the log-likelihood function compared to the corresponding MNL model; however, heterogeneity of some risk attributes turned out not to be statistically significant. So, the standard deviations of the risk of evacuation $\left(\beta_{P e v}\right)$ and the risk of injury $\left(\beta_{P i n j}\right)$ attributes were not statistically significant at least at the 5\% level. This means that variation in individual tastes regarding the valuation of injury and evacuation are statistically negligible and thus fixed coefficients would be a fair representation of the tastes of the whole sample. Variations in the valuation of the fatality risk $\left(\beta_{P f}\right)$ and the constant term (ASC(evacuation)) were statistically significant, and therefore we shall continue with a model where only these two parameters are set random. ${ }^{13}$

\subsection{The selected model}

Based on the results of a number of tested mixed logit model formulations described in the previous section, we selected preferred models (basic and extended) to be estimated, where we have left two random parameters with significant heterogeneity in taste: fatality risk $\left(\beta_{P f}\right)$ and the evacuation alternative constant (ASC(evacuation)). The constant was assumed to be normally distributed, while the coefficient of fatality risk attribute was assumed to have normal, triangular, uniform and log-normal mixing distributions. The models were estimated accounting for the panel structure, and assuming correlation between the two random attributes. The short models A (with choice attributes only) were estimated using 500, 1,000 and 5,000 Halton draws, and we can see that estimated parameters (and thus VOSL as well as VOSI and VOSE) are sufficiently stable (see Tables 4, 5 and 6). The improvement in the log-likelihood function for all estimated models, compared to MNL models, is substantial and is statistically highly significant.

Mean VOSL values for the basic model (A) are about €6.7 mln with normal, uniform and triangular mixing distributions of fatality risk coefficient; for the log-normal distribution VOSL is about $€ 6.3 \mathrm{mnl}$ (see Table 4). All these values remain fairly close to the multinomial estimate of $€ 6.8 \mathrm{mln}$.

\footnotetext{
${ }^{13}$ Recalling footnote 8 , we may conclude that both observed heterogeneity and unobserved heterogeneity in the valuation of the risks of injury and evacuation appear to be not statistically significant.
} 
Table 4. Basic model (A) and extended model (B): mixed logit with mixing distributions for ASC(evacuation) and $\mathrm{P}($ fatal) and with panel structure - mean VOSL estimates (in mln $€){ }^{\text {a }}$

\begin{tabular}{|c|c|c|c|c|}
\hline \multirow{2}{*}{$\begin{array}{l}\text { Model A } \\
\text { basic MNL model }\end{array}$} & \multicolumn{4}{|c|}{ Mean VOSL value in mln $€$} \\
\hline & \multicolumn{4}{|c|}{6.835} \\
\hline mixing distribution for $\mathrm{P}($ fatal $)$ attribute & normal & triangular & uniform & lognormal \\
\hline 500 draws & 6.938 & 6.921 & 6.927 & $29,336.290$ \\
\hline 1,000 draws & 6.725 & 6.744 & 6.727 & 6.281 \\
\hline 5,000 draws & 6.749 & 6.741 & 6.724 & 6.318 \\
\hline Model B & \multicolumn{4}{|c|}{ Mean VOSL value in mln $€$} \\
\hline extended MNL model (weighted) & \multicolumn{4}{|c|}{7.040} \\
\hline mixing distribution for $\mathrm{P}($ fatal $)$ attribute & normal & triangular & uniform & lognormal \\
\hline 1,000 draws & 7.172 & 7.172 & 7.167 & 6.919 \\
\hline 5,000 draws & 7.197 & 7.184 & 7.171 & 6.985 \\
\hline
\end{tabular}

a mixing distribution for ASC(evacuation) - normal; correlations between attributes included.

Extended models (B, where also socio-economic covariates were included in the utility function defined as in [3a, b]) were estimated with 1,000 and 5,000 Halton draws, and also show robust results. An example of such a model is found in Table $\mathrm{C} 3$ in the Appendix with assumed normal distributions of the risk parameter and the constant, for the case of 5,000 Halton draws. The number of observations is 2,685 (537 respondents, 5 choice cards each). We can see that all estimated parameters of the choice attributes are statistically significant at least at a $5 \%$ level, including $P$ (injury) beta that was not significant in the MNL models. Standard deviations of the two random parameters are significant, which supports an assumption that there is substantial individual heterogeneity in their valuation. The cross-correlation between the fatality risk parameter and the constant term ASC(evacuation) found in below-diagonal value in Cholesky matrix is statistically insignificant. Moreover, the diagonal terms from Cholesky decomposition matrix resemble the standard deviations of the random coefficients, which provides no evidence for cross-correlation between the two estimated parameters. Finally, this model also shows a very decent improvement in log-likelihood with pseudo $\mathrm{R}^{2}$ of 0.28 that is a clear advancement in the function fit compared to the respective MNL model with pseudo $\mathrm{R}^{2}$ of 0.14 ; AIC drops (see Tables $\mathrm{C} 1$ and $\mathrm{C} 3$ ).

In Table $\mathrm{C} 4$ we present the results of an extended mixed logit model where also socio-economic covariates are included. Among the covariates, only interaction terms with the dummies for age, health 
condition and residence in the rural areas turned to be statistically significant. We can see that younger respondents (between 18 and 35), urban residents as well as respondents with very good self-reported health condition ( 8 to 10 on the scale of 0 to 10 ) have a lower willingness to pay for the improvements in flood safety compared to older respondents, rural residents and respondents in a less good health condition, all other things held constant. The adverse effect of age on WTP might initially seem somewhat counterintuitive (Bočkarjova et al. 2009), provided the arguments on fewer expected life-years for older respondents. However, empirical studies provide mixed results on the age-VOSL relationship (Alberini et al. 2004 and 2006, Krupnick 2007, Kim et al. 2009, Cameron et al. 2010). ${ }^{14}$ A possible explanation for increasing WTP with age in our case may come from the side of altruism argument (also found by Grolleau et al. 2009), when older people are in fact paying not only for their own decrease in the risk of premature fatality, but rather for that of the following generation that should be 'secure' of flood safety (this position of older respondents was also observed during the pilot).

We shall further compare the obtained indicators of VOSL, VOSI and VOSE from all mixed models with various assumed distributions for the risk parameter (we recall that $A S C$ (evacuation) parameter is in all models assumed to be normally distributed). We start with VOSL.

Results of the extended model (B) estimations are also reported in Table 4. Here, mean VOSL estimates are about $€ 7.2 \mathrm{mln}$ for the normal, triangular and uniform distributions, and $€ 7.0 \mathrm{mln}$ for the $\log$ normal, compared to the VOSL of $€ 7.0 \mathrm{mln}$ from the multinomial logit estimation (all values are weighted at sample average values of the covariates).

Taking a closer look at the distribution of VOSL values throughout the mixed logit models (see Table 7), we can get an impression about the distributions. We have simulated valuations of the beta for fatality risk attribute $(\mathrm{N}=10,000)$ for all four distributions: normal, triangular, uniform and log-normal.

This exercise has revealed some differences in the results that were nearly invisible when we looked at the mean VOSL values. Now, we can see that various distributions also produce various percentages of negative individual risk valuations per simulated population. For the basic model these are mere $2.8 \%$ for the normal distribution of the fatality risk parameter, $14.5 \%$ for the uniform distribution and a substantial

\footnotetext{
${ }^{14}$ Also other literature in health studies (like Gyrd-Hansen 2003, Olsen and Donaldson 1998) support the decreasing WTP with age due to the decreasing quality-adjusted life-years. However, also studies on the value of statistical lifeyears, VOSLY, (Hammit 2007) provide mixed results on the age-WTP relationship.
} 
$26.5 \%$ for the case of triangular distribution. Lognormal distribution by construction produce no negative valuations. So, for the basic model without covariates, lognormal distribution comes out to have the smallest range of VOSLs, from 2.4 to $€ 12.8 \mathrm{mln}$, followed by normal distribution with $€ 0.95$ to $€ 12.5 \mathrm{mln}$ (we should note that while the mean values are about the same for the normal and lognormal distributions, the highest simulated value of VOSL with the assumed log-normal distribution is twice as high as that of the normal one, respectively, $€ 39.6 \mathrm{mln}$ vs $€ 18.8 \mathrm{mln}$ ). Uniform and triangular distributions contain negative valuations in the $90 \%$ confidence interval: from $€-1.9$ to $€ 15.3 \mathrm{mln}$ and from $€-10.1$ to $€ 23.9 \mathrm{mln}$, respectively.

For the extended model formulation we have about the same fractions of negative valuations for the respective mixing distribution of the risk parameter, which translates into the respective estimated $90 \%$ confidence interval of the VOSL valuations compared to the basic model. We should note that for the extended model our computations were based on the mean covariate values, i.e. for a person with 'sampleaverage' characteristics. We thus suspect that factual variation of VOSL within some sub-groups in the sample (such as men or women, high- or low-income respondents, or respondents with high or low level of schooling) might be higher than the variation reported in Table 5.

Table 5. Mixed logit with panel structure (5,000 Halton draws) - mean values of VOSL estimates in mln $€$; mixing distribution for ASC(evacuation) - normal.

\begin{tabular}{|c|c|c|c|c|}
\hline mixing distribution for $\mathrm{P}(\mathrm{fatal})$ attribute & normal & triangular & uniform & lognormal \\
\hline \multicolumn{5}{|l|}{ Model A } \\
\hline Mean VOSL basic model (A) & 6.75 & 6.74 & 6.70 & 6.30 \\
\hline$\%$ negative $\mathrm{VOSL}^{\mathrm{a}}$ & $2.84 \%$ & $26.46 \%$ & $14.52 \%$ & $0.00 \%$ \\
\hline Lower bound $\mathrm{CI}(90 \%)^{\mathrm{a}}$ & 0.95 & -10.10 & -1.87 & 2.41 \\
\hline Upper bound $\mathrm{CI}(90 \%)^{\mathrm{a}}$ & 12.52 & 23.85 & 15.30 & 12.76 \\
\hline \multicolumn{5}{|l|}{ Model B } \\
\hline $\begin{array}{l}\text { Mean VOSL extended model (weighted at } \\
\text { covariate sample average values) - (B) }\end{array}$ & 7.25 & 7.40 & 7.17 & 7.00 \\
\hline$\%$ negative $\operatorname{VOSL}^{\mathrm{a}}$ & $2.17 \%$ & $25.41 \%$ & $13.21 \%$ & $0.00 \%$ \\
\hline Lower bound $\mathrm{CI}(90 \%)^{\mathrm{b}}$ & 1.29 & -9.76 & -1.55 & 3.09 \\
\hline Upper bound CI $(90 \%)^{\mathrm{b}}$ & 13.08 & 24.66 & 15.93 & 13.13 \\
\hline
\end{tabular}

The negative valuations that we obtain in the mixed logit estimations are essentially not unexpected due to the imposed symmetry underlying the three unrestricted distributions (normal, triangular and 
uniform), and high heterogeneity in tastes for fatal risk reduction. The amount of negative risk valuations much depends on the chosen distribution. It is important to note here that estimates of mean VOSL as well as confidence interval for VOSL with assumed mixing lognormal distribution for the risk parameter, which is restricted to positive valuations and thus often produces inflated estimates, provide values that are very close to the normal distribution, which is symmetric and unrestricted. This observation provides some further evidence in favour of stability of the estimated parameters throughout various distributions, and thus robustness of the valued VOSL indicator that account for the panel structure of the data and individual heterogeneity in tastes.

Table 6. Basic model (A) and extended model (B): mixed logit with mixing distributions for ASC(evacuation) and P(fatal) and with panel structure - mean value of injury (VOSI) estimates in $€{ }^{\mathrm{a}}$

\begin{tabular}{|c|c|c|c|c|}
\hline Model A & \multicolumn{4}{|c|}{ Mean VOSI value in $€$} \\
\hline basic MNL model & \multicolumn{4}{|c|}{92,183} \\
\hline $\begin{array}{l}\text { mixing distribution for } \mathrm{P}(\text { fatal }) \\
\text { attribute }\end{array}$ & normal & triangular & uniform & lognormal \\
\hline 500 draws & 91,170 & 90,939 & 90,529 & 99,013 \\
\hline 1,000 draws & 91,367 & 91,382 & 90,965 & 91,994 \\
\hline 5,000 draws & 91,768 & 91,365 & 90,961 & 91,629 \\
\hline Model B & \multicolumn{4}{|c|}{ Mean VOSI value in $€$} \\
\hline extended MNL model (weighted) & \multicolumn{4}{|c|}{95,689} \\
\hline $\begin{array}{l}\text { mixing distribution for } \mathrm{P}(\text { fatal }) \\
\text { attribute }\end{array}$ & normal & triangular & uniform & lognormal \\
\hline 1,000 draws & 101,627 & 101,419 & 101,171 & 101,506 \\
\hline 5,000 draws & 101,840 & 101,505 & 101,181 & 101,192 \\
\hline
\end{tabular}

a mixing distribution for ASC(evacuation) - normal; correlations between attributes included.

The valuations of evacuation and of injury follow the same pattern as VOSL (see Tables 6 and 7) and also resemble a robust pattern. So, mean VOSI for the basic model is found in the range of $€ 91,000$ to $€ 92,000$, while the reference multinomial point estimate of VOSI is $€ 92,200$. For the multivariate model these values are slightly higher, mean VOSI for the mixed models varies between $€ 101,200$ and $€ 101,800$ compared to the MNL estimate of VOSI of $€ 95,700$. 
Table 7. Basic model (A) and extended model (B): mixed logit with mixing distributions for ASC(evacuation) and P(fatal) and with panel structure - mean value of evacuation (VOSE) estimates in $€ .^{\text {a }}$

\begin{tabular}{|c|c|c|c|c|}
\hline Model A & \multicolumn{4}{|c|}{ Mean VOSE value in $€$} \\
\hline basic MNL model & \multicolumn{4}{|c|}{2,517} \\
\hline $\begin{array}{l}\text { mixing distribution for } \mathrm{P}(\text { fatal }) \\
\text { attribute }\end{array}$ & normal & triangular & uniform & lognormal \\
\hline 500 draws & 2,396 & 2,393 & 2,387 & 2,386 \\
\hline 1,000 draws & 2,385 & 2,379 & 2,376 & 2,321 \\
\hline 5,000 draws & 2,383 & 2,380 & 2,377 & 2,333 \\
\hline Model B & \multicolumn{4}{|c|}{ Mean VOSE value in $€$} \\
\hline extended MNL model (weighted) & \multicolumn{4}{|c|}{2,554} \\
\hline $\begin{array}{l}\text { mixing distribution for } \mathrm{P}(\text { fatal }) \\
\text { attribute }\end{array}$ & normal & triangular & uniform & lognormal \\
\hline 1,000 draws & 2,404 & 2,399 & 2,394 & 2,356 \\
\hline 5,000 draws & 2,402 & 2,399 & 2,396 & 2,371 \\
\hline
\end{tabular}

${ }^{\mathrm{a}}$ mixing distribution for ASC(evacuation) - normal; correlations between attributes included.

The estimation of the mean value of evacuation is about $€ 2,400$ for both basic and extended models, for all distributions of the fatality risk coefficient, which is meticulously close to the VOSE of $€ 2,500$ from the MNL estimates.

\section{Composite valuation of immaterial damages}

So far we have presented separate measures of immaterial damages in this paper, namely VOSL, VOSI and VOSE. However, it is just as important to know how each of the indicators contributes to the entire picture of immaterial damages, in case all of which are going to be used in cost-benefit analyses. For this purpose, we can use VOSL as an anchor, and so express the other two immaterial damages in relation to single VOSL (see also Zhai et al. 2003, and Penning-Rowsell et al. 2005). This means that we need to establish relationships between the expected numbers of fatalities, injuries and evacuated persons.

\subsection{Injuries vs fatalities}

The number of injured persons per one fatality depends on the type of flood, and might be different for various types of injuries (for example, a flash flood opposed to a dike overtopping). However, a number of longitudinal studies have shown that this ratio is pretty stable if we take a historical average of multiple events and various types of injuries. For example, in Japan the ratio of deaths to injuries is 1 to 10 (Zhai et 
al. 2006), for the US it is 1 to 6 (Ashley and Ashley 2008). This means that it would be reasonable to assume for our case an approximate ratio of deaths to injuries between 1 to 5 and 1 to 10 . In relative terms, given the level of VOSI of $€ 92,000$ and VOSL of $€ 6.8 \mathrm{mln}$, the mark-up factor of the value of injuries per 1 fatality makes about 0.07 to 0.14 of VOSL. So in monetary terms, it would expectedly take about 74 injured persons to add to the total immaterial damage amount as much as 1 fatal incident.

\subsection{Evacuations vs fatalities}

Further, we need to establish the number of evacuated persons per one fatality. This requires more information, as evacuation and flood events have different frequencies and involve various groups of people. The number of expected evacuated persons per year would depend on the number of residents of an area at risk (in the Netherlands these are dike-rings), fraction of evacuated persons per event $(\eta)$ and the yearly probability of evacuation $\left(P_{\text {evacuation }(y e a r l y)}\right)$, or:

$$
E\left(N_{\text {evacuated persons }}\right)=N_{\text {total }} \cdot \eta \cdot \underset{(\text { evearly })}{P_{\text {evation }}}
$$

The expected number of fatalities per year in an area at risk would depend on the extent of flood in terms of affected persons ( $\alpha$, if not the whole area is flooded), the fraction of non-evacuated persons (1- $\eta$ ) assuming it is the same throughout the whole area as the extent of flood is not known beforehand; the fraction of fatalities per flood event $(\varphi)$ and the yearly probability of a flooding $\left(P_{\text {flood (yearly) }}\right)$, or:

$$
E\left(N_{\text {fatalities }}^{\text {per year }}\right)=N_{\text {total }} \cdot \alpha \cdot(1-\eta) \cdot \varphi \cdot P_{\text {flood }} \text { (yearly) }
$$

We define the ratio of frequency of evacuations to the frequency of floods as $\lambda$ :

$$
\frac{P_{\text {evacuation }}}{(\text { yearly })}=\lambda
$$

Combining expressions [4]-[6], the ratio of evacuated persons to the number of fatalities, $v$, is:

$$
\frac{E\left(N_{\text {evacuated persons }}\right)}{E\left(N_{\text {fatalities }}\right)} \equiv v=\frac{\lambda \cdot \eta}{(1-\eta) \cdot \alpha \cdot \varphi}
$$

Expression [7] shows that $v$ depends on the number of evacuations per flood $(\lambda)$, the extent of flood in the area $(\alpha)$, the fraction of residents evacuated $(\eta)$ and those who remain in the area at risk $(1-\eta)$, and the fraction of deaths per flood event $(\varphi)$. So, the more frequent the evacuations, the more people get evacuated 
and the fewer fatalities are expected per flood event, the higher the $v$ indicator. ${ }^{15}$ This means that in the areas where extreme water levels can be predicted well in advance (like riverside) most residents can be evacuated and few die, the ratio of evacuated persons to fatalities will be high. In other areas, where flood warnings are short (often, in the coastal areas), and few people can preventively be evacuated, the ratio of evacuated persons to fatalities will be low, also because more fatalities could be expected.

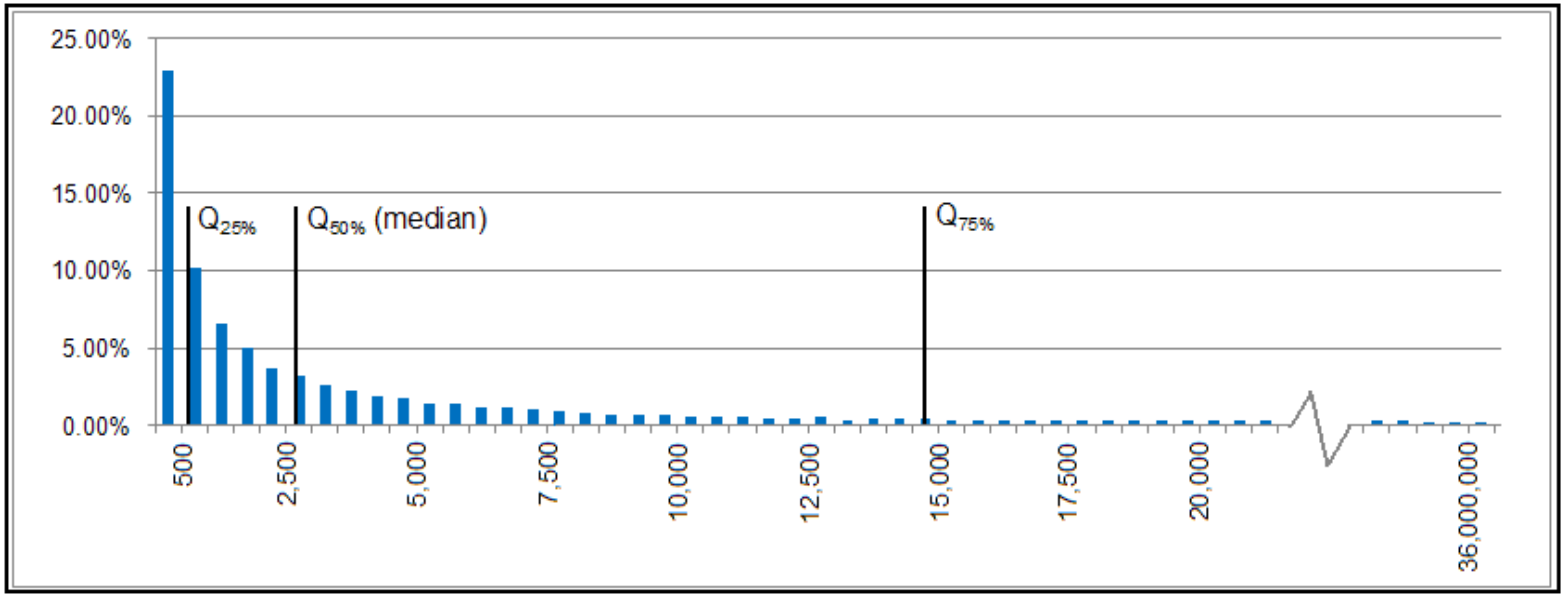

Figure 2. Simulated frequency distribution of the the ratio of evacuated persons to the number of fatalities, $v$ (in intervals of 500).

Assumed ranges of parameters, uniformly distributed: $5 \%$ to $95 \%$ in 10 steps of $10 \%$ for the number of evacuations per flood $(\lambda)$, the extent of flood in the area $(\alpha)$, the fraction of residents evacuated $(\eta)$; and a restricted range of $0.1 \%$ to $10.1 \%$ (with 10 steps of $1 \%$ ) for the fraction of deaths per flood event $(\varphi)$.

The ratio of evacuated persons to the number of fatalities is calculated following the formulae $v=\frac{\lambda \cdot \eta}{(1-\eta) \cdot \alpha \cdot \varphi}$. Depicted quartiles: $\mathrm{Q}_{25 \%}=580 ; \mathrm{Q}_{50 \%}($ median $)=2,716 ; \mathrm{Q}_{75 \%}=14,357$.

In order to have a better idea about the spread of the ratio of evacuated persons to the number of fatalities, we have constructed a simulated distribution for the $v$ parameter. We have thus considered the following ranges of dependent parameters: $5 \%$ to $95 \%$ uniformly distributed in 10 steps of $10 \%$ for the ratio of evacuations to floods $(\lambda)$, the fraction of persons affected $(\alpha)$, the fraction of residents evacuated $(\eta)$. For the fraction of deaths per flood event $(\varphi)$, we restricted the selected range to the more realistic numbers found between $0.1 \%$ and $10.1 \%$ (with 10 steps of $1 \%$ ). ${ }^{16}$ In Figure 2 the distribution of the $v$ parameter is displayed. We see that for the selected ranges of $\lambda, \alpha, \eta$ and $\varphi$, the simulated distribution of $v$ is characterized by a high frequency in the low values, and a relatively long right-hand tail. So, almost $23 \%$ of values are

\footnotetext{
${ }^{15}$ Note that in cost-benefit terms, the optimal evacuation frequency is the one where the inconvenience costs of another evacuation is equal to the probability that an accident occurs times the expected value of immaterial damage. Material damage does not matter in the determination of the optimal frequency of evacuation, because it remains unaffected by the evacuation.

${ }^{16}$ See Jonkman (2007) for a literature overview on the average death rate in flooding.
} 
below 500 evacuees per fatality, and almost as much, $21 \%$ are above 20,000 , spreading up to the maximum of $36,100,000$. The right tail is getting progressively thinner as the values of $v$ increase: only about $12.5 \%$ of the simulated values fall in the range of above $50,000,2.5 \%$ - above 500,000 and merely $0.25 \%$ - above $5,000,000$. The median is 2,716 and the $90 \%$ confidence interval for this distribution of $v$ is found between 67 and $190,900$.

Due to the fact that $\varphi$, the fraction of deaths per flood event, ${ }^{17}$ is directly and inversely related to $v$, the ratio of evacuated persons to the number of fatalities, the final value of $v$ is highly sensitive to the assumed range of $\varphi$ (we shall see it illustrated in the sample calculations for two typical areas below). So, the lower the $\varphi$, the higher the $v{ }^{18}$

Table 8. Main parameters for the analysis of evacuation inconvenience.

\begin{tabular}{|c|c|c|c|}
\hline & Parameter & Coastal area & Riverside \\
\hline Probability of flooding & $P_{\text {flood }}$ & $1 / 10,000$ & $1 / 1,250$ \\
\hline Probability of evacuation $^{a}$ & $\begin{array}{c}P_{\text {evacuation }} \\
(\text { yearly })\end{array}$ & $1 / 200$ & $1 / 200$ \\
\hline ratio of evacuations to floods & $\lambda$ & 50 & 6.25 \\
\hline fraction of persons evacuated ${ }^{a}$ & $\eta$ & 0.15 & 0.75 \\
\hline fraction of persons affected $^{a}$ & $\alpha$ & 0.40 & 0.65 \\
\hline fraction of fatalities ${ }^{b}$ & $\varphi$ & $1 \%-5 \%$ & $0.1 \%-1 \%$ \\
\hline Number of evacuated persons to one fatality ${ }^{c}$ & $v$ & $441-2,206$ & $2,885-28,846$ \\
\hline $\begin{array}{l}\text { Mark-up factor for the value of evacuation } \\
\text { per one VOSL }^{\mathrm{d}}\end{array}$ & $\kappa$ & $0.16-0.78$ & $1.02-10.18$ \\
\hline
\end{tabular}

${ }^{a}$ Source: HKV (2010)

${ }^{\mathrm{b}}$ Source: Klijn et al. (2004)

${ }^{\mathrm{c}}$ The ratio of evacuated persons to the number of fatalities is calculated following the formulae $v=\frac{\lambda \cdot \eta}{(1-\eta) \cdot \alpha \cdot \varphi}$.

${ }^{\mathrm{d}}$ Mark-up factor for the value of evacuation per one VOSL is calculated following the formulae $\kappa=v \cdot \operatorname{VOSE} / \operatorname{VOSL}$. Assumed VOSE is $€ 2,400$ and VOSL is $€ 6.8 \mathrm{mln}$.

\footnotetext{
${ }^{17}$ The same is true for parameter $\alpha$, the extent of flood in the area. However, on a more practical level, the expected value of $\alpha$ should not vary greatly across various regions. Alternatively, parameter $\varphi$, the fraction of deaths per flood event, may differ by factor 10 or even 50 across the regions (as we shall see, expected fraction of fatalities at the riverside may be as low as $0.01 \%$ of affected population, and reach up to $5 \%$ in the coastal areas).

${ }^{18}$ For comparison, we have simulated another distribution of the ratio of evacuees to fatalities (let's call it $v_{l}$ ) for the values of $\varphi$ found between $5 \%$ to $95 \%$ in 10 steps of $10 \%$, just as the assumed ranges of the other three indicators, $\lambda, \alpha$ and $\eta$. Now, the distribution of $v_{l}$ has 'moved leftwards' with a median of 33 , the $90 \%$ confidence interval between 1 and 90,000, and a maximum of 361,000 .
} 
Because the $v$ indicator has a relatively wide spread, we may expect that composition of immaterial damage varies across the areas different in terms of flood characteristics. We shall illustrate this by taking examples of two typical regions in the Netherlands. Let us start with an example of a dike-ring on the riverside. For the estimates of the parameters $\lambda, \alpha$ and $\eta$ from formulae [7] we rely on the calculations done by HKV (2010) - see Table 8 . Here, the projection is that evacuations will take place 6.25 times more often than floods (respective probabilities are once in 200 years vs once in 1,250 years). Experience shows that extreme water levels here can be forecasted at least 1 week beforehand, and therefore there is enough time for evacuation from the area for most of its residents. In most of the riverside areas about $65 \%$ of the inhabitants will get affected by a flood; and three quarters of the inhabitants would get evacuated per event. More uncertainty exists, however, with regard to the fraction of fatalities per event, as it depends on such factors as the type of flooding (overtopping or breaching of dikes), time of the year and time of the day, and on the weather conditions. It would, however, be reasonable to assume that the fraction of fatalities per flood event $(\varphi)$ for the riverside areas would be found between $0.1 \%$ and $1 \%$ (Klijn et al., 2004). This means that we can obtain various ratios of evacuated persons to the number of fatalities: for $\varphi_{1}=1 \%, v_{\text {river }(\varphi 1)}$ will be 2,885 . If this percentage decreases to $\varphi_{2}=0.1 \%$, then $v_{\text {river }\left(\varphi^{2}\right)}$ will proportionately increase to 28,846 .

A different picture would be observed in the coastal areas in the Netherlands, where storm surges from the sea pose flood danger. The dike-ring of Central Holland is a typical coastal area with high population density and the highest protection level in the country, 1 in 10,000 per year. Here, HKV (2010) calculations show that evacuations are expected to be as frequent as at the riverside, 1 in 200 years (Table 8). This means that here the ratio of evacuations to floods is 50 to 1 . Provided a relatively short warning time for coastal storm surges (24 to $48 \mathrm{~h}$ ), high population density, the extent of the area, and limited escape capacities, evacuation fraction would be expected to be low, reaching on the average $15 \%$. It would be very unlikely if not impossible - that the entire area of Central Holland is flooded; most floods would probably cover only a part of the dike-ring (depending on the place and the number of breaches), so that $\alpha$ would expectedly be about $40 \%$ in most scenarios. However, if a flood takes place, it would probably be a severe event characterized by high water depths, reaching in some places 4 to $6 \mathrm{~m}$. This means that we may expect a high fraction of human victims: $1 \%$ to $5 \%$ of people found in flooded area might die (Klijn et al., 2004). So, the ratio of evacuated persons to one fatality $\left(v_{\text {coast }}\right)$ would range in such coastal area between 440 and 2,200. 
Positioning the obtained ranges of $v_{\text {coast }}$ and $v_{\text {river }}$ for the two typical dike-ring areas in the Netherlands in the simulated distribution for the ratio of evacuated persons to one fatality (Figure 2), we can see that the range of $v_{\text {coast }}(440 ; 2,200)$ is found below the median $(2,716)$; and the range of the $v_{\text {river }}(2,880 ; 28,850)$ is found just above the median. Both ranges fall within the $\mathrm{CI}_{90 \%}$ interval of $v$ : so, slightly more than a quarter (26.3\%) of values of $v$ will be found within the $v_{\text {coast }}$ range, and about a third $(32.3 \%)$ - within the $v_{\text {river }}$ range. $20 \%$ of this simulated $v$ ratio distribution will fall below 400 , and $17 \%$ - above 30,000 .

\subsection{Composition of immaterial damages}

The relationship between the expected number of evacuees and fatalities can easily be translated in value terms, and represented as a mark-up factor, or perhaps a 'surcharge', for the value of evacuation per one VOSL, $\kappa$ :

$$
\kappa=v \cdot \operatorname{VOSE} / V O S L
$$

Applying formulae [8], and assuming typical values of VOSL and VOSE (€6.8 $\mathrm{mln}$ and $€ 2,400$, respectively, see Section 4), we can also construct a distribution for this mark-up factor. Figure 3 depicts the distribution of $\kappa$ per decile of the evacuees-fatalities ratio distribution $(v)$. So, we can see that about in half of the cases, value of evacutation will contribute up to a one VOSL to the total immaterial damages. In the other half of the cases, however, the mark-up factor $\kappa$ will be higher than a single VOSL; for the last $10 \%$ of cases $\kappa$ will lie above 25, up to almost 13,000 at the extreme. This explosive increase in $\kappa$ is traced back to the long thin right-hand-side tail that we have observed by the $v$ distribution (see Figure 2). For the two typical flood-prone areas in the Netherlands, the respective mark-up factors will be as follows. For the

riverside, $\kappa_{\text {river }}$ for the value of evacuation per one VOSL would then range roughly between 1 to 10 (similar results on fatality vs injury costs were obtained by Viscusi and Zeckhauser, 1994). For the coastal areas, $\kappa_{\text {coast }}$ would make 0.16 to at most 0.78 . 


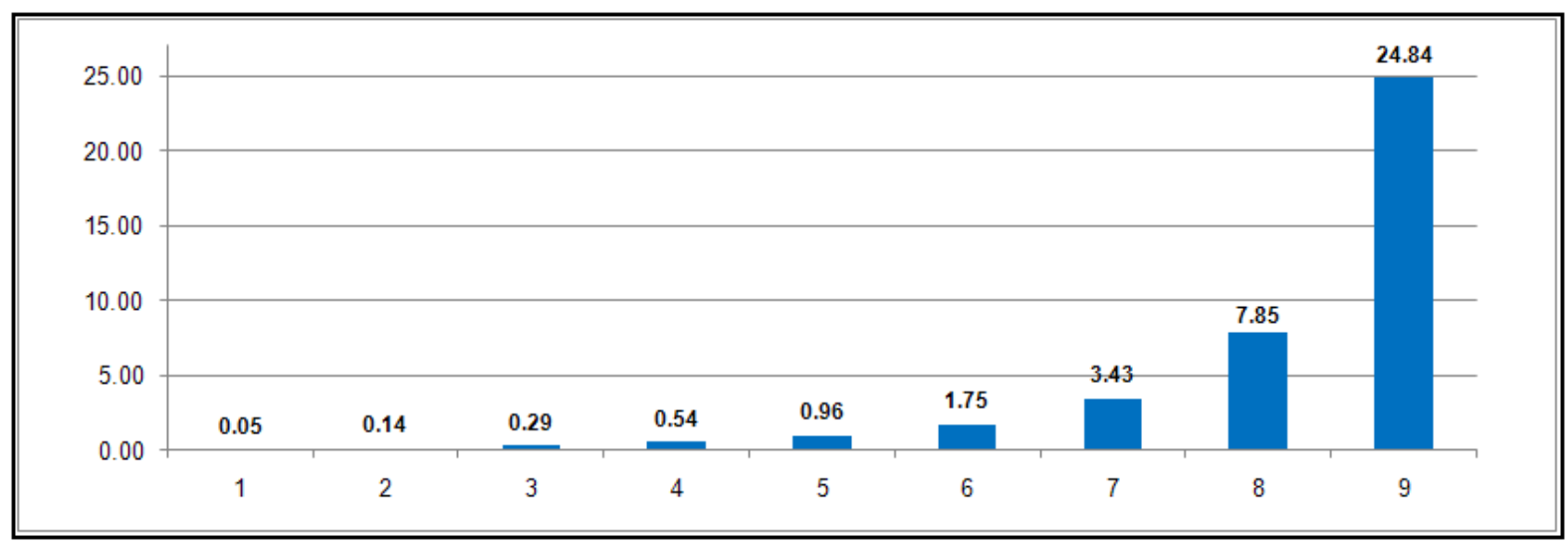

Figure 3. Mark-up factor for the value of evacuation per one VOSL ( $\kappa)$, depicted per decile of the evacueesfatalities ratio distribution $(v)$.

Mark-up factor for the value of evacuation per one VOSL is calculated following the formulae $\kappa=v \cdot V O S E / V O S L$. Assumed VOSE is $€ 2,400$ and VOSL is $€ 6.8 \mathrm{mln}$.

Finally, to provide a ready-to-use overview, the injury, evacuation and fatality components can be expressed in percent of the total composition of immaterial damages. Because the value of evacuation can result in highly varying mark-up factors per one VOSL, the final composition of immaterial damages will depend on the particular values of $v$ and $\kappa$. For the sake of illustration, we shall pick the middle points of the ranges for $\kappa_{\text {river }}$ and $\kappa_{\text {coast }}$ (5 and 0.5 , respectively), and see with which composition we will end up for the riverside and the coastal areas. From Figure 4 we learn that injuries make up the smallest portion of total immaterial damages in both cases; for the rest the two pictures are chalk and cheese. So, for the coastal areas, fatalities make up almost two thirds of the total immaterial damages $(62.5 \%)$, and evacuation - about a third (31\%). In the riverside areas, almost $82 \%$ of all immaterial damages are made up by the evacuation inconvenience and about one sixth (16.4\%) - by fatalities. We recall that the two charts on Figure 4 are based on the mid-point values of $\kappa_{\text {river }}$ and $\kappa_{\text {coast }}$. For more extreme, though not unrealistic, cases of $\kappa_{\text {river }}=$ 10 and $\kappa_{\text {coast }},=0.15$, the relative composition of the immaterial damages would get even more skewed to the side of evacuations for the riverside areas (up to $90 \%$ ), and to the side of fatalities for the coastal areas (up to $80 \%$ ). Clearly, the final composition of immaterial damages will depend on the number of factors connected to the nature of flood in the area. 


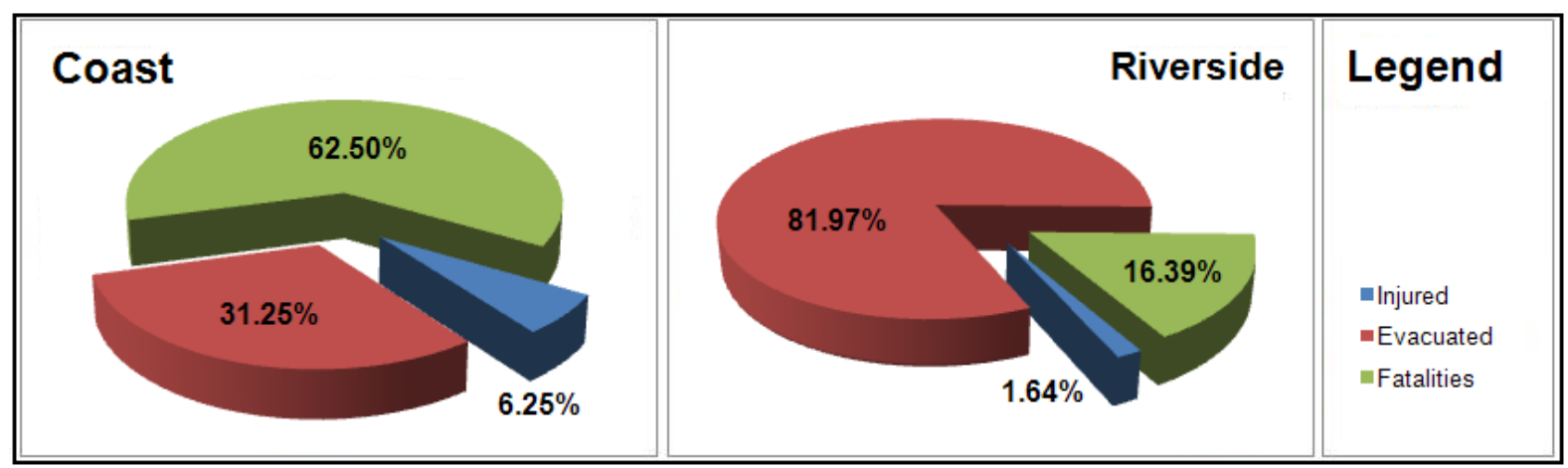

Figure 4. Composition of total immaterial damages per dike-ring area (in percent).

Assumptions: average expected mark-up factor of value of injuries per 1 fatality (coast and river: $\kappa_{I N J}=0.1$ ), average expected mark-up factors of value of evacuation per $1 \mathrm{VOSL}\left(\kappa_{E V A C \text {.coast }}=0.5 ; \kappa_{E V A C \text {.river }}=5\right)$. Typical values of immaterial damage are: VOSI $=€ 92,000, \operatorname{VOSE}=€ 2,400, \mathrm{VOSL}=€ 6.8 \mathrm{mln}$.

We note that when using this approach for policy assessments, a researcher should beware of the effects that policy measures themselves may have on the composite valuation of immaterial damages. So, some proposed measures aiming at reducing total expected immaterial damages, such as raising the dikes, would lead to a more or less proportional reduction in the expected numbers of fatalities, injuries and evacuations, so that $v$ and $\kappa$ are expected to stay fixed for flood conditions dominating in a particular area. Alternatively, other measures, such as introduction of more stringent rules for evacuation resulting in more expected evacuations per one fatality, would increase the expected number of evacuations, but may decrease the expected numbers of fatalities and injuries. So, this may change $v$ and $\kappa$, and thus the relative weights of the immaterial damage components, but the resulting effect on the total value of immaterial damage is uncertain. Here, composite valuation of immaterial damage can help defining the optimal number of evacuations that would minimize the total value of immaterial damage.

To summarise our findings, we observe that while it seems that VOSI obtained in Section 4 in absolute terms is a sizeable indicator $(€ 92,000)$, on the aggregate level the value of injury is a relatively minor contributor relative to fatalities and evacuations to the total composite value of immaterial damages. This has to do with a relatively low expected number of injuries per one fatality in the event of a flood. Alternatively, a relatively moderate estimate of $\operatorname{VOSE}(€ 2,400)$, perhaps somewhat unexpectedly, has on average proven to add a more substantial surcharge on the total value of immaterial damages. Due to high variability in parameters that are necessary to determine the relation between the number of evacuated persons and one fatality, this ratio has a distribution with a long tail. So, the particular level of the 
evacuation mark-up factor per VOSL depends on the area in question and is directly related to the nature of flood risk. Namely, in areas where floods can be forecasted well in advance (like in the case of river floods) and the majority of residents can be evacuated on a regular basis, the total value of evacuation can be a number of times higher than the total value of fatalities. At the same time, in the areas where flood warnings are short (like in the case of storm surges in the coastal areas), evacuations are less massive and expected fatalities are relatively high, the contribution of value of evacuation would make up less than that of fatalities.

\section{Conclusions and policy implications}

This study is based on a survey on the valuation of flood risk conducted in 2008 in four flood-prone areas in the Netherlands. The proposed level of fatality risk was small (in the range of $10^{-6}$ to $10^{-5}$ ) compared to a range usually valued in similar studies. The current study has also offered a separate simultaneous valuation of fatality risk, VOSL, value of statistical injury and value of statistical evacuation, which presumably also resulted in unconfounded VOSL estimate (see Bočkarjova et al. 2010). It is also new to the valuation literature that VOSL is estimated in the natural hazard context. Moreover, simultaneously estimated and well validated VOSI and VOSE in the context of flooding are not known to the authors.

Our following conclusion is that numerically, our obtained indicators are plausible and reflect findings elsewhere in the literature. The resulting mean VOSL is about 6.3-7.2 million euros per additional statistical life saved, or fatality avoided; the value of evacuation inconvenience, mean VOSE, is between 2,300-2,500 euros per evacuation; and the value of inconvenience associated with injury, VOSI, is 91,000-102,000 euros per injury. Concerning the technical part of this study, we can conclude that, first, in all mixed logit models (basic and extended) the estimated risk parameters, and thus the indicators of our interest - VOSL, VOSE and VOSI - remain robust across the various assumed distributions. Second, all average parameter estimates from mixed logit models are also found within narrow margins from the respective point estimates obtained in the multinomial logit models. Both these findings provide evidence in favour of a fair degree of reliability of our estimates.

Our final conclusion is that it is important to consider other indicators (such as VOSI and VOSE suggested here) alongside with VOSL to obtain the total value of immaterial damages. The total composition 
of immaterial damages would further depend on the nature of flood risk in a particular area. So, if we take a look at the composition of immaterial damages in the Netherlands (Figure 4), adding together the costs of fatalities, injuries and evacuations, we can see that value of injuries would contribute no more than $10 \%$ to the total immaterial damages. The value of evacuation, however, appears to be less predictable, and varies depending on the area and the nature of flood danger. For example, in the riverside areas in the Netherlands where extreme water levels can timely be predicted and the majority of residents can be evacuated, the value of evacuation would be relatively high, making up $3 / 4$ to $9 / 10$ of the total immaterial damages depending on the assumptions about the frequency of evacuations, fraction of evacuated persons per event and fraction of fatalities per flooding. For the coastal areas where storm surges are less predictable and where only a small fraction of inhabitants can timely be evacuated, evacuations surcharge per one fatality would be substantially lower and vary, again depending on the circumstances, from $1 / 3$ to $1 / 2$ of the total immaterial damages. Fatalities, on the other hand, would make up here at least a half of the total costs.

Our findings on the magnitude and composition of valuated immaterial damages have a number of implications for policy that are of general character as well as specific to the situation in the Netherlands. First, valuation of fatality risk in flood (a typical VOSL of $€ 6.8 \mathrm{mln}$ ) is higher than the respective indicator obtained in the context of transport safety (VOSL $=€ 2.2 \mathrm{mln}$, see Wijnen et al. 2009) and that is currently adopted in CBA of flood protection measures in the Netherlands. This pleads for a higher monetary value of benefits in relation to avoided fatalities connected to better flood protection measures. Second, composite valuation of immaterial damage shows the importance of including differentiated indicators of immaterial damage alongside with valued fatalities (VOSL) in cost-benefit analyses, such as value of statistical injury (VOSI) and value of statistical evacuation (VOSE), which can substantially contribute to the composite value of avoided immaterial damages. As we have shown, under some risk conditions the VOSL might make but a fraction of total immaterial damages, and so inclusion of the VOSL alone in a cost-benefit analysis may not be representative of total immaterial damages, and in some cases even significantly underestimate these. Finally, the observed discrepancy in the relative weights of various components of immaterial damage (and we have considered only three of them in this study) between various areas with 
differing flood risks points at the necessity to consider area-specific immaterial damages when conducting CBA, also provided the effects that particular policy measures may have on the expected height and composition of immaterial damages.

\section{Acknowledgements}

This research was financed by the BSIK project Climate Changes Spatial Planning (Klimaat voor Ruimte, see www.klimaatvoorruimte.nl) and project KBA WV21 from the Dutch Ministry of Transport and Water Management. Further we are indebted to Jarl Kind and Bas Jonkman for their valuable comments in the starting phase of this research. All remaining faults are those of the authors only.

\section{References}

Ahern, M., Kovats, R.S., Wilkinson, P., Few, R., Matthies, F., 2005. Global Health Impacts of Floods: Epidemiologic Evidence. Epidemiologic Reviews 27, 36-46.

Alberini, A., Cropper,M., Krupnick, A., Simon, N., 2004. Does the value of a statistical life vary with age and health status? Evidence from the US and Canada. Journal of Environmental Economics and Management 48, 769-792.

Alberini, A., Šcasný, M., 2011. Context and the VSL: Evidence from a Stated Preference Study in Italy and the Czech Republic. Environmental and Resource Economics 49(4), 511-538.

Ashley, S.T., Ashley, W.S., 2008. Flood Fatalities in the United States. Journal of Applied Meteorology and Climatology 47, 805-818.

Baskaran, R., Cullen, R., Colombo, S., 2010. Testing different types of benefit transfer in valuation of ecosystem services: New Zealand winegrowing case studies. Ecological Economics 69, 1010-1022.

Bellavance, F., Dionne, G., Lebeau, M., 2009. The value of statistical life in road safety: a meta-analysis with a mixed effects regression model. Journal of Health Economics 28, 444-464.

Bočkarjova, M., Rietveld, P., Verhoef, E.T., 2008a. Review of pilot questionnaire results, IC5 Report within the research programme Climate changes spatial planning. VU Amsterdam, June 2008.

Bočkarjova, M., Rietveld, P., Verhoef, E.T., 2008b. Valuation of Flood Risk in the Netherlands: Some Preliminary Results. In: S. Martorell, C. Guedes Soares \& J. Barnett (Eds.), Safety, Reliability and Risk Analysis: Theory, Methods and Applications. Taylor \& Francis, pp. 2781-2788.

Bočkarjova, M., Rietveld, P., Verhoef, E.T., 2009. First results of immaterial damage valuation: value of statistical life (VOSL), value of evacuation (VOSE) and value of injury (VOSI) in flood risk context, a stated preference study (III), IC5 Report within the research programme Climate changes spatial planning. VU Amsterdam, December 2009.

Bočkarjova, M., Rietveld, P., Verhoef, E.T., 2010. Context analysis of multiple stated choice experiments: scale, scope and cognition. Paper presented at the Workshop on Risk Elicitation and Stated Preference Methods for Climate Change Research, 21-22 October 2010, Trento, Italy. 
Bonnichsen, O., Ladenburg, J., 2010. Reducing status quo bias in choice experiments: An application of a protest reduction entreaty. FOI Working Paper 2010 / 7. Institute of Food and Resource Economics, University of Copenhagen.

Botzen, W.J.W., Aerts, J.C.J.H., van den Bergh, J.C.J.M., 2009. Willingness of homeowners to mitigate climate risk through Insurance. Ecological Economics 68, 2265-2277.

Cameron, T.A., DeShazo, J.R., Stiffler, P., 2010. Demand for health risk reductions: A cross-national comparison between the U.S. and Canada. Journal of Risk and Uncertainty 41, 245-273.

Chernev, A., 2004. Goal orientation and consumer preference for the status quo. Journal of Consumer Research 31, 557-565.

Costanza, R., Farley, J., 2007. Ecological economics of coastal disasters: Introduction to the special issue. Ecological Economics 63, 249-253.

Daniel, V.E., Florax, R.J.G.M., Rietveld, P., 2009. Flooding risk and housing values: An economic assessment of environmental hazard. Ecological Economics 69, 355-365.

De Blaeij, A., 2003. The value of a statistical life in road safety: stated preference methodologies and empirical estimates for the Netherlands. PhD thesis, Tinbergen Institute Research series No 308, Amsterdam.

De Blaeij, A., Florax, R.J.G.M., Rietveld, P., Verhoef, E.T., 2003. The value of statistical life in road safety: a meta-analysis. Accident Analysis and Prevention 35, 973-986.

De Brabander, B., 2007. De waardering van dodelijke verkeersslachtoffers in Vlaanderen; Resultaten van een contingente waardering in Vlaanderen. Report Nr.RA-2007-111, Steunpunt Verkeersveiligheid, Diepenbeek, Belgium.

Dekker T., Brouwer R., Hofkes M., Moeltner K., 2011. The Effect of Risk Context on the Value of a Statistical Life: a Bayesian Meta-model. Environmental and Resource Economics 49(4), 597-624.

Frankhauser, S., Tol, R.S.J., 1996. Climate change costs: Recent advancements in the economic assessment. Energy Policy 24, 665-673.

Frankhauser, S., Tol, R.S.J., Pearce, D.W., 1998. 'Extensions and Alternatives to Climate Change Damage Valuation: On the Critique of IPCC Working Group III's Damage Estimates'. Environment and Development Economics 3, 59-81.

Grolleau, G., Ibanez, L., Mzoughi, N., 2009. Too much of a good thing? Why altruism can harm the environment? Ecological Economics 68, 2145-2149.

Gyrd-Hansen, D., 2003. Willingness to pay for a QALY. Health Economics 12, 1049-1060.

Hammit, J.K., 2007. Valuing changes in mortality risk: Lives saved versus life years saved. Review of Environmental Economics and Policy 1, 228-240.

Hensher, D.A., Rose, J.M., Greene, W.H., 2008. Applied choice analysis: A primer. Cambridge: Cambridge University.

HKV, 2010. Kentallen evacuatie voor kostenbaten analyse. Memorandum PR1919-10, Lelystad.

Jonkman, S.N. (2007). Loss of life estimation in Flood risk assessment. Theory and applications. PhD Thesis. Delft University of Technology.

Jonkman, S.N., Bočkarjova, M., Kok, M., Bernardini, P., 2008. Integrated hydrodynamic and economic modelling of flood damage in the Netherlands. Ecological Economics 66, 77-90.

Jonkman, S.N., Maaskant, B., Boyd, E., Levitan, M.L., 2009. Loss of Life Caused by the Flooding of New Orleans after Hurricane Katrina: Analysis of the Relationship Between Flood Characteristics and Mortality. Risk Analysis 29, 676-698.

Kim, B.H.S., Kim, E., Lee, J., Son, M., 2009. Elicitation of Health Values from Mortality Risk reduction. The Social Science Journal, 46, 776-786. 
Klijn, F., van der Klis, H., Stijnen, J., de Bruijn, K., Kok, M., 2004. Overstromingsrisico dijkringen in Nederland; betooglijn en deskundigenoordeel. HKV Lijn in Water, Rapport Q3503.10, April.

Kluve, J., Schaffner, S., 2008. The Value of Life in Europe - a Meta-Analysis. Sozialer Fortschritt 10-11, 279-287.

Kolen, B.; Helsloot, I. (2012) Time needed to evacuate the Netherlands in the event of large-scale flooding: strategies and consequences. Disasters, 36(4), in press.

Kolen, B.; Maaskant, B.; Helsloot, I.; Thonus, B. (2010) EvacuAid: probabilistic evacuation model to determine expected loss of life for different strategies for mass evacuation. Paper presented at International Conference on Emergency Preparedness (InterCEPt), The Challenges of Mass Evacuation, 21 - 23 September 2010, Birmingham, UK.

Kontoleon, A., Yabe, M., 2003 -Assessing the impacts of alternative 'opt-out' formats in choice experiment studies: consumer preferences for genetically modified content and production information in food. Journal of Agricultural Policy and Research 5, 1-43.

Krupnick, A., 2007. Mortality-risk Valuation and Age: Stated Preference Evidence. Review of Environmental Economics and Policy 1(2), 261-282.

Olsen, J.A., Donaldson, C., 1998. Helicopters, hearts and hips: using willingness to pay to set priorities for public sector health care programmes. Social Science and Medicine 46, 1-12.

Penning-Rowsell, E., Peter Floyd, W., Ramsbottom, D., Surendran, S., 2005. Estimating Injury and Loss of Life in Floods: A Deterministic Framework. Natural Hazards 36, 43-64.

Richardson, L., Loomis, J., 2009. The total economic value of threatened, endangered and rare species: An updated meta-analysis. Ecological Economics 68, 1535-1548.

Shanmugam, K.R., 2000. Valuations of Life and Injury Risks; Empirical Evidence from India. Environmental and Resource Economics, 16, 379-389.

Sunstein, C.R., 2000. Cognition and Cost-Benefit Analysis. The Journal of Legal Studies 29, 1059-1103.

Svensson, M., 2009. The value of a statistical life in Sweden: Estimates from two studies using the "Certainty Approach" calibration. Accident Analysis \& Prevention 41, 430-437.

Terpstra, T., 2010. Flood preparedness: thoughts, feelings and intentions of the Dutch public. PhD thesis, Universiteit Twente, Albani drukkers, The Hague.

Tseng, Y.Y., 2008. Valuation of travel time reliability in passenger transport. PhD thesis, Tinbergen Institute Research series No 439, Amsterdam.

Van Dantzig, D., 1956. Economic decision problems for flood prevention. Econometrica 24(3), 276-287.

Viscusi, W.K., Aldy, J.E., 2003. The Value of a Statistical Life: A Critical Review of Market Estimates Throughout the World. Journal of Risk and Uncertainty 27, 5-76.

Viscusi, W.K., Zeckhauser, R.J., 1994. The Fatality and Injury Costs of Expenditures. Journal of Risk and Uncertainty 8, 19-41.

Wijnen, W., Wesemann P., de Blaeij, A., 2009. Valuation of road safety effects in cost-benefit analysis. Evaluation and Program Planning 32, 326-331.

WL|Delft Hydraulics \& HKV Lijn in Water, 2004. Overstromingsrisico dijkringen in Nederland: betooglijn en deskundigenoordeel. Report, Delft.

WL|Delft Hydraulics, 2007. Overstromingsrisico's in Nederland in een veranderd klimaat; verwachtingen, schattingen en berekeningen voor het project Nederland Later. Report, Delft.

Zhai, G., 2006. Public Preference and Willingness to Pay for Flood Risk Reduction. In: S. Ikeda, T. Fukuzono, and T. Sato (Eds.), A better integrated management of disaster risks: Toward resilient society to emerging disaster risks in mega-cities. TERRAPUB and NIED, pp. 57-87.

Zhai, G., Fukuzono, T. Ikeda, S., 2006. An Empirical Model of Fatalities and Injuries Due to Floods in Japan. Journal of the American Water Resources Association 42, 863-875. 
Zhai, G., Fukuzono, T., Ikeda, S., 2003. An Empirical Model of Efficiency Analysis on Flood Prevention Investment in Japan. Review of Urban \& Regional Development Studies 15, 238-254. 


\section{Appendix A: DESCRIPTION OF THE CHOICE EXPERIMENT}

The choice situation was described as follows (translation from Dutch) and was accompanied by a sample choice card as shown below:

"Imagine that you have decided to move for some overriding reason, and you are considering buying a house. You have seen two identical houses that suit your requirements in terms of the type of house, number of bedrooms, surface/volume and land, and they have the same price.

Both houses are located in a polder, and these polders are equivalent: equally big, beautiful, accessible, the residential areas have same provisions and comfort, etc. These characteristics should not play a role in your decision which house you will buy.

In one of the polders (A), flood can be predicted in advance and an evacuation arrangement is in place, which means that every inhabitant of the polder is obliged to comply with an evacuation bevel. In this case, the plan will work well and all the inhabitants of the polder will be evacuated on time so that no one runs a risk of dying in a flood if it takes place. Note, that in case evacuation takes place, it will approximately last for 1 week.

On the other hand, in the other polder (B), it is not possible to predict flood enough in advance to carry out preventive evacuation. This means, that evacuation in this polder is not possible, and you, just as every polder resident, are running some risk of dying or getting an injury in a flood. In case of injury, you might think of broken parts, contusions, blunt traumas, lacerations hypothermia, electrical shocks, for which hospitalisation would be necessary.

You also have to pay a water board tax in each polder, which is spent on flood protection.

Answering this question, consider only the probabilities of flood and preventive evacuation, the expected number of flood fatalities and injuries. Please, ignore for a moment the presence of all other risks connected to an event of flood (assume, for example, that government will compensate all your material damages if a flood takes place).

Try to consider all shown characteristics.

You will see five screens with choice possibilities, where every time the levels of the shown characteristics will change.

In which polder would you prefer to buy a house?" 


\begin{tabular}{|c|c|c|}
\hline & POLDER A & POLDER B \\
\hline & $\begin{array}{l}\text { Possibility for } \\
\text { evacuation }\end{array}$ & $\begin{array}{l}\text { No possibility for } \\
\text { evacuation }\end{array}$ \\
\hline $\begin{array}{l}\text { Probability of flooding } \\
\text { in your place of residence } \\
\text { (in the coming } 50 \text { years) }\end{array}$ & 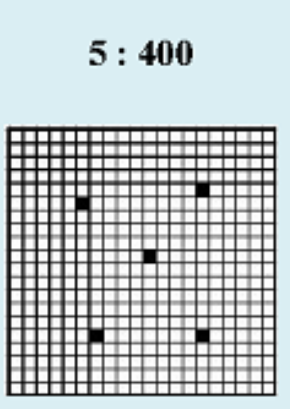 & 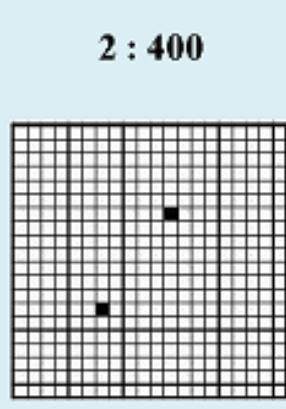 \\
\hline $\begin{array}{l}\text { Probability of evacuation } \\
\text { in the place of residence } \\
\text { (in the coming } 50 \text { years) }\end{array}$ & $20: 400$ & $\mathbf{0}$ \\
\hline $\begin{array}{l}\text { Probability that you become a } \\
\text { flood victim } \\
\text { (in the coming } 50 \text { years) }\end{array}$ & $\mathbf{0}$ & $2: 40.000$ \\
\hline $\begin{array}{l}\text { Probability of getting an injury } \\
\text { (in the coming } 50 \text { years) }\end{array}$ & $\mathbf{0}$ & $10: 40.000$ \\
\hline Water board tax (yearly) & $€ 25$ & E55 \\
\hline Your choice (please mark one box) & $\square$ & $\square$ \\
\hline
\end{tabular}




\section{Appendix B: ATTRIBUTE LEVELS USED IN THE CHOICE EXPERIMENT}

Alternative with a possibility for evacuation:

$\mathrm{P}$ (evacuation) in the coming 50 years -5 levels:

$10: 400 \quad 25: 400 \quad 50: 400 \quad 100: 400 \quad 200: 400$

Local community Tax per year -3 levels:

$€ 60 \quad € 80 \quad € 100$

Alternative without a possibility for evacuation:

$\mathrm{P}$ (fatality) in the coming 50 years -5 levels:

$2: 40,000 \quad 5: 40,000 \quad 10: 40,000 \quad 15: 40,000 \quad 20: 40,000$

$\mathrm{P}$ (injury) in the coming 50 years -5 levels:

$20: 40,000 \quad 50: 40,000 \quad 100: 40,000 \quad 150: 40,000 \quad 200: 40,000$

Local community Tax per year -3 levels:

$€ 30 \quad € 40 \quad € 45$ 


\section{Appendix C: tabLES}

Table C1. MNL estimate: a short model.

\begin{tabular}{|c|c|c|c|c|}
\hline Variable & Coeff. & std.error & P-value & Sign. \\
\hline \multicolumn{5}{|l|}{ CE ATTRIBUTES } \\
\hline ASC(evacuation) & 1.109 & 0.163 & 0.0000 & $* * *$ \\
\hline $\mathrm{P}($ evacuation $)$ & -0.036 & 0.009 & 0.0000 & $* * *$ \\
\hline $\mathrm{P}$ (fatality) & -97.506 & 12.985 & 0.0000 & $* * *$ \\
\hline $\mathrm{P}$ (injury) & -1.315 & 0.867 & 0.1294 & \\
\hline TAX & -14.266 & 2.170 & 0.0000 & $* * *$ \\
\hline N observations (choice cards) & 2685 & & & \\
\hline Log likelihood function & -1600 & & & \\
\hline Restricted log likelihood function & -1861 & & & \\
\hline Pseudo R2 & 0.1403 & & & \\
\hline Adjusted R2 & 0.1387 & & & \\
\hline AIC & 1.1956 & & & \\
\hline VOSL ${ }^{*}$ & $€ 6.835 \mathrm{mln}$ & & & \\
\hline VOSE (value of stat. evacuation) & $€ 2,517$ & & & \\
\hline VOSI (value of stat. injury) & $€ 92,183$ & & & \\
\hline
\end{tabular}

$*, * *, * * *$ - statistical significance at respectively $10 \%, 5 \%$ and $1 \%$ level. 
Table C2. MNL estimate: an extended model.

\begin{tabular}{|c|c|c|c|c|}
\hline Variable & Coeff. & std.error & P-value & Sign. \\
\hline \multicolumn{5}{|l|}{ CE ATTRIBUTES } \\
\hline ASC(evacuation) & 1.10 & 0.164 & 0.0000 & $* * *$ \\
\hline $\mathrm{P}($ evacuation$)$ & -0.04 & 0.009 & 0.0000 & $* * *$ \\
\hline P(fatality) & -104.76 & 16.01 & 0.0000 & $* * *$ \\
\hline $\mathrm{P}$ (injury) & -1.35 & 0.878 & 0.1229 & \\
\hline TAX & -6.89 & 2.951 & 0.0197 & $* *$ \\
\hline \multicolumn{5}{|l|}{ COVARIATES } \\
\hline $\begin{array}{l}\text { Interaction with Tax attribute } \\
\text { INCOME high } \\
\text { (8-10 deciles) }\end{array}$ & 3.03 & 2.67 & 0.2557 & \\
\hline No INCOME stated & -3.67 & 2.07 & 0.0764 & * \\
\hline University degree $(\mathrm{HBO}+)$ & -2.77 & 2.06 & 0.1782 & \\
\hline AGE $18-34$ & -15.77 & 2.63 & 0.0000 & $* * *$ \\
\hline Good HEALTH (8 to 10$)$ & -3.76 & 1.90 & 0.0470 & $* *$ \\
\hline GENDER (male) & 0.47 & 1.90 & 0.8037 & \\
\hline Own PROPERTY & -2.37 & 2.07 & 0.2539 & \\
\hline \multicolumn{5}{|l|}{ Interaction with $P($ fatality) attribute } \\
\hline RURAL & -39.30 & 26.25 & 0.1343 & \\
\hline \multirow{2}{*}{$\begin{array}{l}\text { Coastal area } \\
\text { OWN experience } \\
\text { (flood / evacuation) }\end{array}$} & -0.32 & 14.95 & 0.9832 & \\
\hline & 44.07 & 17.95 & 0.0141 & $* *$ \\
\hline N observations (choices) & 2685 & & & \\
\hline Log likelihood function & -1569 & & & \\
\hline Restricted log likelihood function & -1861 & & & \\
\hline Pseudo R2 & 0.157 & & & \\
\hline Adjusted R2 & 0.152 & & & \\
\hline AIC & 1.180 & & & \\
\hline VOSL $^{\ddagger}$ & $€ 7.040 \mathrm{mln}$ & & & \\
\hline VOSE (value of stat. evacuation) & $€ 2,554$ & & & \\
\hline VOSI (value of stat. injury) & $€ 95,689$ & & & \\
\hline
\end{tabular}

$*, * *, * * *$ - statistical significance at respectively $10 \%, 5 \%$ and $1 \%$ level.

$\$$ - weighted at covariate sample means 
Table C3. Mixed logit estimate with normal mixing distribution for random parameters ASC(evacuation) and $\mathrm{P}(\mathrm{fatal})$ and with panel structure: a short model (5,000 Halton draws).

\begin{tabular}{|c|c|c|c|c|}
\hline Variable & Coeff. & std.error & P-value & Sign. \\
\hline \multicolumn{5}{|l|}{ CE ATTRIBUTES } \\
\hline ASC(evacuation) & 2.860 & 0.367 & 0.0000 & $* * *$ \\
\hline $\mathrm{P}($ evacuation $)$ & -0.085 & 0.013 & 0.0000 & $* * *$ \\
\hline $\mathrm{P}$ (fatality) & -239.773 & 45.744 & 0.0000 & $* * *$ \\
\hline $\mathrm{P}$ (injury) & -3.260 & 1.484 & 0.0281 & $* *$ \\
\hline TAX & -35.526 & 3.515 & 0.0000 & $* * *$ \\
\hline \multicolumn{5}{|l|}{ STD. RANDOM PARAMETERS } \\
\hline Std. ASC (evacuation alternative) & 3.838 & 0.457 & 0.0000 & $* * *$ \\
\hline Std. P(fatality) & 124.916 & 46.835 & 0.0076 & $* * *$ \\
\hline \multicolumn{5}{|l|}{ DIAGONAL VALUES IN CHOLESKY MATRIX } \\
\hline ASC(evacuation) & 3.838 & 0.457 & 0.0000 & $* * *$ \\
\hline $\mathrm{P}$ (fatality) & 126.205 & 46.733 & 0.0069 & $* * *$ \\
\hline \multicolumn{5}{|l|}{$\begin{array}{l}\text { BELOW DIAGONAL VALUES IN CHOLESKY } \\
\text { MATRIX }\end{array}$} \\
\hline ASC(evacuation) : P(fatality) & -17.989 & 72.544 & 0.8042 & \\
\hline N observations (choices) & 2685 & & & \\
\hline Iterations completed & 28 & & & \\
\hline Log likelihood function & -1157 & & & \\
\hline Restricted log likelihood function & -1861 & & & \\
\hline Pseudo R2 & 0.277 & & & \\
\hline Adjusted R2 & 0.275 & & & \\
\hline AIC & 0.868 & & & \\
\hline VOSL ${ }^{\ddagger}$ & $€ 6.749 \mathrm{mln}$ & & & \\
\hline VOSE (value of stat. evacuation) & $€ 2,383$ & & & \\
\hline VOSI (value of stat. injury) & $€ 91,768$ & & & \\
\hline
\end{tabular}

$*, * *, * * *$ - statistical significance at respectively $10 \%, 5 \%$ and $1 \%$ level. 
Table C4. Mixed logit estimate with normal mixing distribution for random parameters ASC(evacuation) and $\mathrm{P}$ (fatal) and with panel structure: an extended model (5,000 Halton draws).

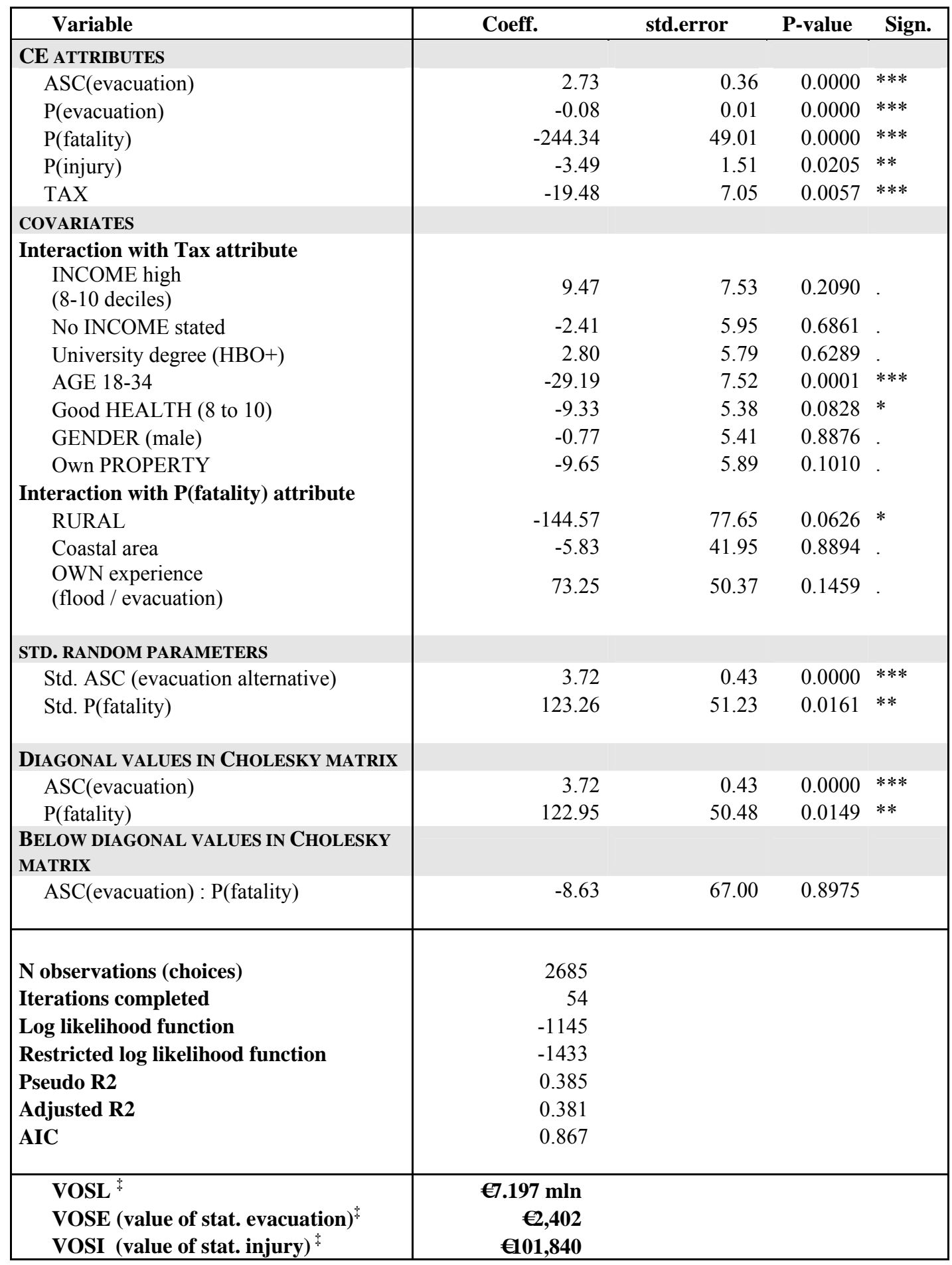

$*, * *, * * *$ - statistical significance at respectively $10 \%, 5 \%$ and $1 \%$ level.

* - weighted at covariate sample means 